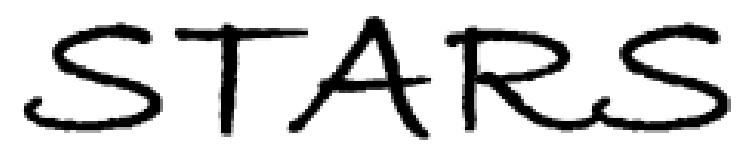

University of Central Florida

STARS

\title{
Role of S/Se ratio in chemical bonding of As-S-Se glasses investigated by Raman, x-ray photoelectron, and extended x-ray absorption fine structure spectroscopies
}

\author{
Wenyan Li \\ University of Central Florida \\ Sudipta Seal \\ University of Central Florida \\ Clara Rivero \\ University of Central Florida \\ Cedric Lopez \\ University of Central Florida \\ Find similar works at: https://stars.library.ucf.edu/facultybib2000 \\ Kathleers Richardsan Florida Libraries http://library.ucf.edu \\ University of Central Florida
}

This Article is brought to you for free and open access by the Faculty Bibliography at STARS. It has been accepted for iferesigrtiA contact STARS@ucf.edu.

\section{Recommended Citation}

Li, Wenyan; Seal, Sudipta; Rivero, Clara; Lopez, Cedric; Richardson, Kathleen; Pope, April; Schulte, Alfons; Myneni, Satish; Jain, Himanshu; Antoine, Keisha; and Miller, Alfred C., "Role of S/Se ratio in chemical bonding of As-S-Se glasses investigated by Raman, $\mathrm{x}$-ray photoelectron, and extended $\mathrm{x}$-ray absorption fine structure spectroscopies" (2005). Faculty Bibliography 2000s. 5401.

https://stars.library.ucf.edu/facultybib2000/5401

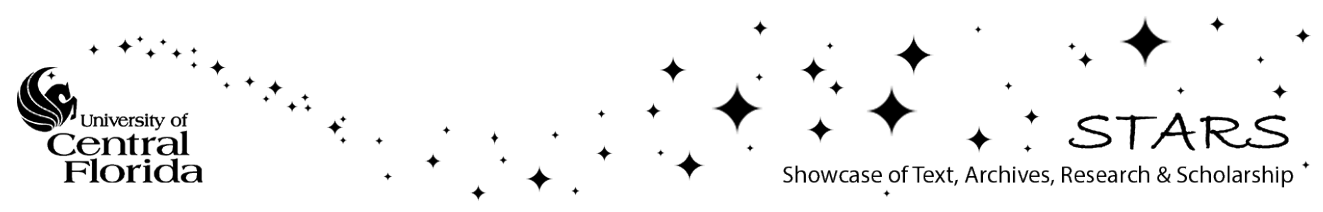




\section{Authors}

Wenyan Li, Sudipta Seal, Clara Rivero, Cedric Lopez, Kathleen Richardson, April Pope, Alfons Schulte, Satish Myneni, Himanshu Jain, Keisha Antoine, and Alfred C. Miller 


\section{Role of $\mathrm{S}$ / Se ratio in chemical bonding of As-S-Se glasses investigated by Raman, $x$-ray photoelectron, and extended x-ray absorption fine structure spectroscopies}

Cite as: J. Appl. Phys. 98, 053503 (2005); https://doi.org/10.1063/1.2009815

Submitted: 15 November 2004 . Accepted: 06 July 2005. Published Online: 02 September 2005

Wenyan Li, Sudipta Seal, Clara Rivero, Cedric Lopez, Kathleen Richardson, April Pope, Alfons Schulte, Satish Myneni, Himanshu Jain, Keisha Antoine, and Alfred C. Miller

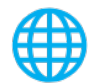

\section{ARTICLES YOU MAY BE INTERESTED IN}

X-ray photoelectron spectroscopic investigation of surface chemistry of ternary As-S-Se chalcogenide glasses

Journal of Applied Physics 92, 7102 (2002); https://doi.org/10.1063/1.1518134

Thermophysical properties and conduction mechanisms in $\mathrm{As}_{x} \mathrm{Se}_{1-x}$ chalcogenide glasses ranging from $x=0.2$ to 0.5

Journal of Applied Physics 120, 145101 (2016); https://doi.org/10.1063/1.4962446

Structural paradigm of Se-rich Ge-Se glasses by high-resolution x-ray photoelectron spectroscopy

Journal of Applied Physics 105, 103704 (2009); https://doi.org/10.1063/1.3130608

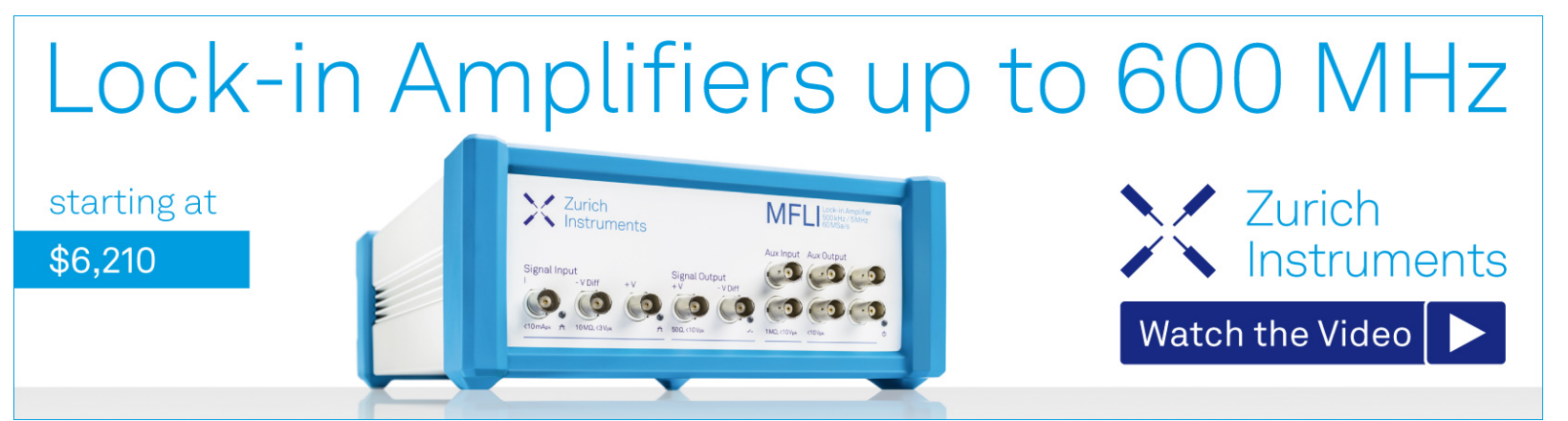




\title{
Role of S/Se ratio in chemical bonding of As-S-Se glasses investigated by Raman, $x$-ray photoelectron, and extended x-ray absorption fine structure spectroscopies
}

\author{
Wenyan $\mathrm{Li}^{\mathrm{a})}$ and Sudipta Seal \\ Advanced Materials Processing and Analysis Center and Mechanical, Materials and Aerospace Engineering \\ Department, University of Central Florida, Orlando, Florida 32816
}

Clara Rivero, Cedric Lopez, and Kathleen Richardson

Center for Research and Education in Optics and Lasers, College of Optics and Photonics, University of Central Florida, Orlando, Florida 32816

April Pope and Alfons Schulte

Department of Physics, University of Central Florida, Orlando, Florida 32816

Satish Myneni

Department of Geosciences, Princeton University, Princeton, New Jersey 08544

Himanshu Jain and Keisha Antoine

Department of Materials Science and Engineering, Lehigh University, Bethlehem, Pennsylvania 18015

\author{
Alfred C. Miller \\ Zettlemoyer Center for Surface Studies, Lehigh University, Bethlehem, Pennsylvania 18015
}

(Received 15 November 2004; accepted 6 July 2005; published online 2 September 2005)

\begin{abstract}
Chalcogenide glasses have attracted considerable attention and found various applications due to their infrared transparency and other optical properties. The As-S-Se chalcogenide glass, with its large glass-formation domain and favorable nonlinear property, is a promising candidate system for tailoring important optical properties through modification of glass composition. In this context, a systematic study on ternary As-S-Se glass, chalcogen-rich versus well-studied stochiometric compositions, has been carried out using three different techniques: Raman spectroscopy, x-ray photoelectron spectroscopy, and extended x-ray absorption fine structure spectroscopy. These complementary techniques lead to a consistent understanding of the role of $\mathrm{S} / \mathrm{Se}$ ratio in chalcogen-rich As-S-Se glasses, as compared to stochiometric composition, and to provide insight into the structural units (such as the mixed pyramidal units) and evidence for the existence of homopolar bonds (such as Se-Se, S-S, and Se-S), which are the possible structural origin of the high nonlinearity in these glasses. (C) 2005 American Institute of Physics. [DOI: 10.1063/1.2009815]
\end{abstract}

\section{INTRODUCTION}

Chalcogenide glasses have attracted considerable attention due to their infrared transparency, low phonon energies, and high nonlinear optical properties. ${ }^{1-5}$ They have been explored as promising materials for optical memories, grating, and switching devices. ${ }^{6-10}$ Recently these glasses are used as core materials for high-efficiency fiber amplifiers as they exhibit high refractive indices and low phonon energies, ${ }^{11-15}$ and as candidate for Raman gain media. ${ }^{16}$

Among chalcogenide glasses, the As-S-Se system is characterized by a large glass-formation domain ${ }^{17}$ and favorable nonlinear properties, ${ }^{4}$ as well as their linear properties. The wide range of glass formation makes this glass system an ideal candidate for tailoring important optical properties through modification of glass composition. ${ }^{4}$ The ease of glass formation makes it desirable for low-loss optical applications. In this context, studies of chemical and structural properties of As-S-Se glasses with different composition are

\footnotetext{
${ }^{a)}$ Author to whom correspondence should be addressed; electronic mail: Wenyan.Li-1@ksc.nasa.gov
}

important for understanding their optical behavior. A systematic study on ternary As-S-Se glass, chalcogen-rich versus well-studied stochiometric compositions, has been carried out, and the results are reported in this paper. The interest in chalcogen-rich compositions is due to the high nonlinearity found in $\mathrm{As}_{24} \mathrm{~S}_{38} \mathrm{Se}_{38}$, which possesses a third-order nonlinearity of 400 times that of silica. ${ }^{4}$

In previous studies, different techniques have been used to understand the structure of chalcogen glasses. Three of them have been proven very effective: Raman spectroscopy, $\mathrm{x}$-ray photoelectron spectroscopy (XPS), and extended x-ray absorption fine structure spectroscopy (EXAFS), to study various chalcogenide glass systems.

Raman spectroscopy has been used to study bulk S-Se, As-S, and As-Se systems, ${ }^{18-25}$ as well as evaporated chalcogenide films of $\mathrm{As}_{2} \mathrm{Se}_{3}$ and $\mathrm{As}_{2} \mathrm{~S}_{3}$, which showed significantly different bonding as compared with bulk quenched glasses. ${ }^{26}$ Our previous study ${ }^{27}$ also revealed significant microstructural difference between unannealed films and fibers drawn from bulk $\mathrm{As}_{2} \mathrm{~S}_{3}$ glasses.

XPS has been used to study the electronic structure of 
chalcogenides, ${ }^{28-31}$ as well as photoinduced structural changes such as photodecomposition, ${ }^{32}$ oxidation, ${ }^{3,34}$ and other compositional changes. ${ }^{35}$ In situ XPS has also been applied to the study of light-induced changes in As-Se glasses. ${ }^{36,37}$ In our previous studies, XPS has been employed to describe the structural changes in $\mathrm{As}_{2} \mathrm{~S}_{3}$ caused by different energy beams ${ }^{38}$ and also the chemical stability of chalcogenide glass under elevated temperatures. ${ }^{39}$

EXAFS is a powerful tool for a detailed and quantitative understanding of the local atomic structure of amorphous materials. $^{26,40-49}$ X-ray absorption spectroscopy (XAS) has been used to study arsenic chalcogen binary compounds and a few compositions in the As-S-Se system. ${ }^{44,50,51}$ A comparison of theoretically and experimentally determined bond strength and chemical order was made in $\mathrm{As}_{x} \mathrm{~S}_{1-x}$, for bulk as well as for film. ${ }^{43,44,52,53}$ EXAFS has also been used to study the photodarkening in amorphous $\mathrm{As}_{2} \mathrm{~S}_{3} .{ }^{54,55}$ The photoinduced formation of dynamical bonds has been observed in amorphous Se by in situ EXAFS. ${ }^{56,57,14}$ Both experimental and theoretical studies have been carried out in As-Se binary glassy system, ${ }^{15,58,59}$ indicating photoinduced Se-related structural changes.

Most previous works have been carried out in arsenic chalcogen binary compounds, and the results ${ }^{18}$ have been interpreted in terms of pyramidal subunits, using the wellaccepted molecular model for $\mathrm{As}_{2}(\mathrm{~S}, \mathrm{Se})_{3}$ glasses proposed by Lucovsky and Martin. ${ }^{60}$ However, the model only predicts vibrational modes for ideal, stochiometric $\mathrm{As}_{2}(\mathrm{~S}, \mathrm{Se})_{3}$ glass compositions, it does not account for modes associated with abnormal bonding configurations (e.g., homopolar bonds or chalcogen-chalcogen bonds) known to be present in stochiometric compositions in small amount, and which are also potentially important configurations found in chalcogen-rich As-S-Se system. ${ }^{4}$

In this paper, we present the findings of a study on the role of S/Se ratio in As-S-Se glasses using Raman XPS, and EXAFS. Raman provides bonding information about different structural groups. XPS provides information on the chemical environment of the three elements as well as the valence band. Through EXAFS, one can gain quantitative information on the atoms' nearest neighbors, including bond length and coordination numbers. This paper aims to explain the variation in S/Se environment in chalcogen-rich As$\mathrm{S}-\mathrm{Se}$ glasses, as compared to stochiometric composition, and to provide insight into the possible existence of abnormally coordinated species (wrong bonds) in these materials.

\section{EXPERIMENTAL PROCEDURE}

\section{A. Sample preparation}

Material compositions were selected from As-S-Se ternary diagram with fixed As content and varying the $\mathrm{S} / \mathrm{Se}$ ratio (Fig. 1). This study has focused on glasses with chalcogen-rich compositions (6-10 on the diagram) and the variation of their structures and properties, as compared to stochiometric compositions, 1-5.

Bulk chalcogenide glass $(\mathrm{ChG})$ samples were prepared by conventional melt quenching in evacuated silica ampoules, using the techniques detailed in Ref. 4. Annealed

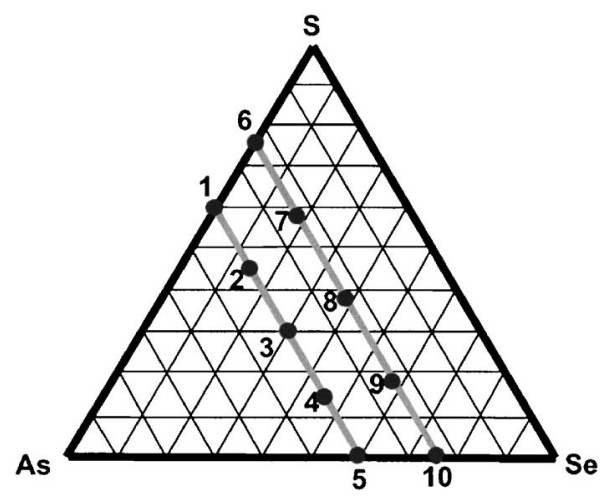

FIG. 1. The ternary composition diagram of the As-S-Se system. The compositions on the diagram is as follows (mol \%): (1) $\mathrm{As}_{40} \mathrm{~S}_{60}$, (2) $\mathrm{As}_{40} \mathrm{~S}_{45} \mathrm{Se}_{15}$, (3) $\mathrm{As}_{40} \mathrm{~S}_{30} \mathrm{Se}_{30}$, (4) $\mathrm{As}_{40} \mathrm{~S}_{15} \mathrm{Se}_{45}$, (5) $\mathrm{As}_{40} \mathrm{Se}_{60}$, (6) $\mathrm{As}_{24} \mathrm{~S}_{76}$, (7) $\mathrm{As}_{24} \mathrm{~S}_{57} \mathrm{Se}_{19}$, (8) $\mathrm{As}_{24} \mathrm{~S}_{38} \mathrm{Se}_{38}$, (9) $\mathrm{As}_{24} \mathrm{~S}_{19} \mathrm{Se}_{57}$, and (10) $\mathrm{As}_{24} \mathrm{Se}_{76}$.

ChG samples were removed from the ampoule, cut, ground, and polished using a Buehler polishing machine. The bulk sample size was $10 \mathrm{~mm}$ in diameter, nominally $2 \mathrm{~mm}$ in average thickness. For XPS experiments, the bulk samples were resized (cut and polished) to $15 \times 5 \times 1.5 \mathrm{~mm}^{3}$ and fractured inside the ultrahigh vacuum chamber of the spectrometer. The composition of bulk samples was verified by energy dispersive $\mathrm{X}$-ray spectroscopy (X-EDS) built in a JEOL 6400F SEM EDS. The composition error was found to be around or less than $1 \mathrm{~mol} \%$.

\section{B. Raman analysis}

High-resolution $\left(1.5 \mathrm{~cm}^{-1}\right)$ Raman spectra on bulk As$\mathrm{S}-$ Se glasses were measured using near-infrared excitation to avoid photoinduced changes in these glasses. Raman scattering was excited at $840 \mathrm{~nm}$ with a Ti:sapphire laser (30-50 $\mathrm{mW}$ ) employing a setup described previously. ${ }^{61,62}$ The scattered Raman light was analyzed with a single-grating spectrograph (Instruments SA, HR 640) equipped with a chargecoupled device (CCD) detector (Princeton Instrument).

\section{XPS analysis}

Bulk glass samples were examined using a Scienta 300 ESCA (Zettlemoyer Center for Surface Studies, Lehigh University) at a vacuum of $\sim 10^{-9}$ Torr. A monochromatic $\mathrm{Al} K \alpha$ x-ray source was used for the analysis; a low-energy electron flood gun was used for charge compensation. Both survey scan and individual high-resolution scans were recorded at a pass energy of 150 V. First, As-S-Se bulk glass samples were fractured inside the XPS vacuum chamber, and data were collected on freshly generated surfaces. Core levels, including As $3 d, \mathrm{Se} 3 d$, and $\mathrm{S} 2 p$ (overlapping with $\mathrm{Se} 3 p$ in ternary glasses), Auger lines, and valence-band data were collected. Then the fractured surfaces were coated with a thin layer (about $2 \mathrm{~nm}$ ) of gold inside the preparation chamber, and the spectra of Au4f and As and Se (when available) core-level spectra were collected. The Au $4 f_{7 / 2}$ line was used as charge reference at $84.00 \mathrm{eV}$. The "true" binding energy of the As3d spectra of the gold-coated sample were obtained 
TABLE I. Raman data fitting parameters (peak position and peak width both in wave number) and peak assignments.

\begin{tabular}{|c|c|c|}
\hline $\begin{array}{c}\text { Peak position } \\
\left(\text { Wave number, } \mathrm{cm}^{-1}\right)\end{array}$ & $\begin{array}{c}\text { Width } \\
\text { (Wave number, } \mathrm{cm}^{-1} \text { ) } \\
\text { (Gaussian/Lorentzian) }\end{array}$ & Peak assignment \\
\hline 212 & $14.5 / 0.007$ & Interaction of the $\mathrm{AsSe}_{3}$ pyramids \\
\hline 227 & $19.6 / 10.3$ & As-Se vibration in $\mathrm{AsSe}_{3}$ pyramidal units \\
\hline 241 & $16 / 1$ & As-Se vibration in $\mathrm{AsCh}_{3}$ units and/or Se-Se chain \\
\hline 257 & $15.87 / 9$ & $\begin{array}{l}\text { As-Se vibration in } \mathrm{AsCh}_{3} \text { units and/or Se-Se ring } \\
\text { fracture }\end{array}$ \\
\hline 269 & $18 / 1.5$ & Interaction of the $\mathrm{AsSe}_{3}$ pyramids \\
\hline 312 & $24.3 / 5.65$ & Interaction of the $\mathrm{AsSe}_{3}$ pyramids \\
\hline 340 & $30 / 10.7$ & As-S vibration in $\mathrm{AsSe}_{3}$ pyramidal units \\
\hline 362 & $17 / 9.8$ & $\begin{array}{l}\text { As-S vibration in } \mathrm{AsCh}_{3} \text { units or interaction between } \\
\qquad \mathrm{AsSe}_{3} \text { and } \mathrm{S}-\mathrm{S} \text { chain }(\sim 365)\end{array}$ \\
\hline 380 & $30 / 7.85$ & Interaction of the $\mathrm{AsSe}_{3}$ pyramids \\
\hline
\end{tabular}

using $\mathrm{Au} 4 f_{7 / 2}$ as a reference, then all the spectra of freshfractured glass surface (before $\mathrm{Au}$ coating) were chargecorrected using As3d as a reference.

\section{EXAFS analysis}

Bulk glass samples were grounded to fine powder for EXAFS experiments. EXAFS data were collected at the Stanford Synchrotron Radiation Laboratory on Beamline 2-3 using $\mathrm{Si}(220)$ monochromator crystals. The slits in front of the monochromator were set at $1.5 \times 14 \mathrm{~mm}$, and the Beamline was detuned by about $50 \%$ above the absorption edge. The data were collected at the As edge in both transmission and fluorescence modes; they were compared and found to be identical.

\section{E. Data analysis}

\section{Raman}

The Raman data were fitted with the GRAMS software, using Voigtian curves appropriate for glasses, which allows one to choose the peak center, height, Gaussian width, and Lorentzian width. The Voigt function is a convolution of both the Gaussian and Lorentzian functions. GRAMS peak fitting uses the Levenberg-Marquardt method. ${ }^{63}$ This is an iterative method that starts with a set of initial values for the peak parameters and modifies them until the variation in the $\chi^{2}$ value, which measures the goodness of the fit, reaches a specified minimum.

These parameters can be set constant or allowed to vary over a range of values. Each composition was fit initially with a minimal set of values. This allowed the software to assign values to optimize the curve-fitting result. Determination of the peak location of each vibrational band was based on previous literature, which allowed for a precise location to be assigned to each band. Once determined, the peak positions were set constant, and the fitting was carried out again. Then for each band the Lorentzian and Gaussian widths were compared over each composition. These values were then averaged and the mean value was used as a constant parameter in additional fits. At this point only the height was allowed to vary, which also determined the area of each band and gave the final fitting results. Raman fitting parameters and peak assignment are listed in Table I.

\section{XPS}

The charge-corrected spectra were analyzed using ESCA Analysis, the XPS data analysis software designed for Scienta ESCA 300 system. As mentioned above, the XPS spectra were charge-corrected using Au coating as reference; then the data were prepared for peak fitting through smoothing and baseline subtraction. Minimal data smoothing was needed due to the good resolution of Scienta ESCA 300 system; Shirley baseline ${ }^{64-66}$ was used for background removal, and the peak ranges were chosen carefully and consistently for different glass compositions. Due to the same reason stated in Sec. II E 1, Voigtian peaks were chosen to carry out peak fitting for each core-level spectrum. First, As3d, Se $3 d$, $\mathrm{S} 2 p$, and $\mathrm{Se} 3 p$ peaks were deconvolved into two-parameter Voigtian peaks, using the parameters in Table II, where $\Delta$ is the doublet separation for $d$ or $p$ orbits; DR is the area ratio for the doublets, such as $3 d_{5} / 3 d_{3}$ or $2 p_{3} / 2 p_{1}$; FWHM is the full width at half maximum of the peaks, and Mix is the Gaussian/Lorentzian mix factor of the peak. The parameters were chosen by using pure elemental data as reference and fitting optimization. As the parameters were chosen, the spectra were fitted with as few peaks as possible. Then through self-consistency of all fitting results and our understanding of the glass system, we assigned the peaks to different chemical environments.

TABLE II. XPS data fitting parameters: $\Delta$ is the doublet binding energy separation for $p$ or $d$ orbits, DR is the area ratio for the doublets, FWHM is the full width at half maximum of the peaks, and Mix is the Gaussian/ Lorentzian mix factor of the peaks.

\begin{tabular}{lllll}
\hline \hline & $\begin{array}{c}\Delta \\
(\mathrm{eV})\end{array}$ & DR & $\begin{array}{c}\text { FWHM } \\
(\mathrm{eV})\end{array}$ & Mix \\
\hline As3d & 0.694 & 0.71 & 0.69 & 0.87 \\
$\mathrm{Se} 3 d$ & 0.85 & 0.76 & 0.75 & 0.93 \\
$\mathrm{Se} 3 p$ & 5.72 & 0.41 & 1.97 & 0.6 \\
$\mathrm{~S} 2 p$ & 1.185 & 0.505 & 0.77 & 0.87 \\
\hline \hline
\end{tabular}




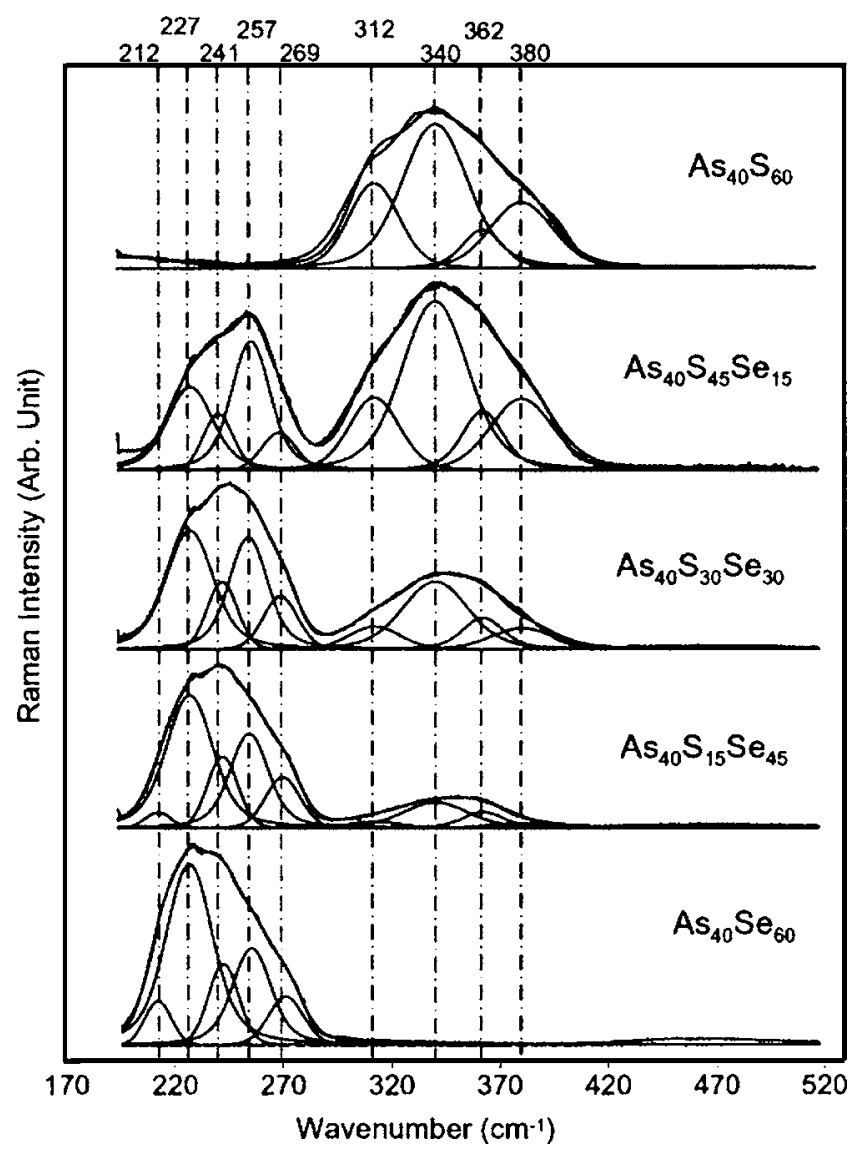

FIG. 2. Raman spectra and deconvolution of bulk chalcogenide glasses $\mathrm{As}_{40} \mathrm{~S}_{60-x} \mathrm{Se}_{x}$.

\section{EXAFS}

A standard procedure was followed to analyze the EXAFS data. ${ }^{67}$ It began with a theoretical calculation of the scattering amplitudes and phase-shift functions of the As-As, As-Se, As-S, Se-Se, and Se-S pairs from As metal, ${ }^{68}$ $c-\mathrm{As}_{2} \mathrm{Se}_{3},{ }^{69} c-\mathrm{As}_{2} \mathrm{~S}_{3}{ }^{70} \mathrm{Se}$ metal, and $c-\mathrm{Se}_{5} \mathrm{~S}_{3}$, respectively, using the FEFF program. ${ }^{71}$ The fitting of the theoretical EXAFS function to the experimental signal was performed in $r$ (or $k$ ) space, using EXAFSPAK XAS software package developed by George at Stanford Synchrotron. ${ }^{72}$

\section{RESULTS}

\section{A. $A s_{40} S_{60-x} \mathrm{Se}_{x}$ glasses $(x=0,15,30,45,60)$ \\ 1. Raman results}

Figure 2 depicts the Raman spectra of chalcogenide stochiometric ternary compounds $\mathrm{As}_{40} \mathrm{~S}_{60-x} \mathrm{Se}_{x}$, where $x=0,15$, 30, 45, 60 (compositions 1, 2, 3, 4, and 5 in Fig. 1). In all cases, $\lambda_{\text {excitation }}=840 \mathrm{~nm}$. The peak-fitting results are also shown in the same figure, and will be discussed later.

The dominant features are two broad bands located at 200-280 and $275-400 \mathrm{~cm}^{-1}$. The relative intensity of the two bands changes monotonically with increasing $x$. As the Se content ( $x$ value) increases, the peak of the scattering intensity in the region $200-280 \mathrm{~cm}^{-1}$ moves toward lower frequencies. Another change observed in the spectra is that the small shoulders at $\sim 210$ and $\sim 275$ become weaker and finally disappear with decreasing Se. The peak shift in the

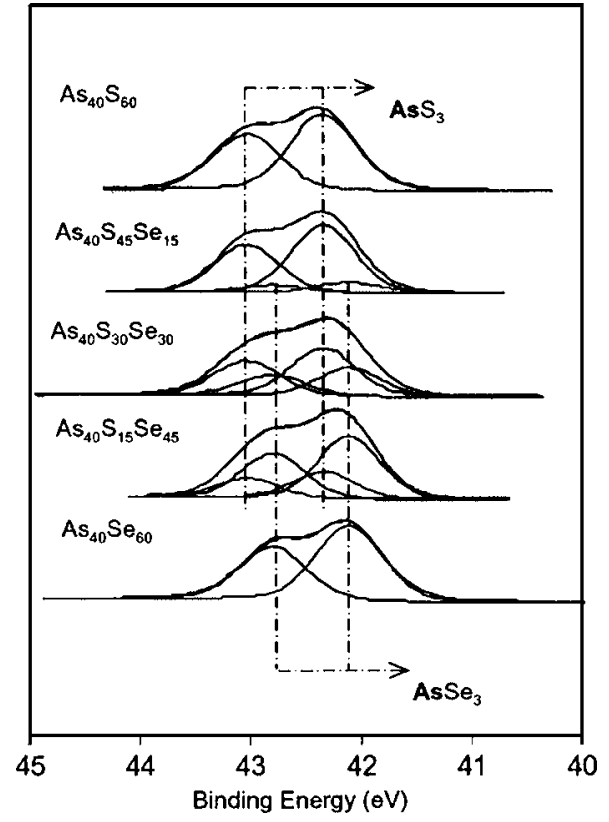

FIG. 3. XPS As3d spectra and deconvolution of bulk chalcogenide glasses $\mathrm{As}_{40} \mathrm{~S}_{60-x} \mathrm{Se}_{x}$.

$280-400 \mathrm{~cm}^{-1}$ is less observable, but the two shoulders at 312 and $380 \mathrm{~cm}^{-1}$ also reduce in intensity and eventually disappear with increasing Se.

\section{XPS results}

XPS results of As $3 d, \mathrm{Se} 3 d, \mathrm{~S} 2 p$ and $\mathrm{Se} 3 p$ and the valence band spectra of $\mathrm{As}_{40} \mathrm{~S}_{60-x} \mathrm{Se}_{x}$ bulk glasses are plotted in Figs. 3-6, respectively. The corresponding peak-fitting results are also shown in the same figures, and will be discussed later.

From the As3 $d$ spectra (Fig. 3), we observe that in $\mathrm{As}_{40} \mathrm{~S}_{60-x} \mathrm{Se}_{x}$, with Se increasing from 0 to $60 \mathrm{~mol} \%$, the binding energy of As $3 d_{5 / 2}$ decreases from $42.34\left(\mathrm{As}_{40} \mathrm{~S}_{60}\right)$ to $42.11 \mathrm{eV}\left(\mathrm{As}_{40} \mathrm{Se}_{60}\right)$. The decrease is small, yet well above the experimental uncertainty, which is $0.05 \mathrm{eV}$. Figure 4 shows a small decrease in the binding energy of $\mathrm{Se} 3 d_{5 / 2}$ peak from $53.84\left(\mathrm{As}_{40} \mathrm{~S}_{45} \mathrm{Se}_{15}\right)$ to $53.93 \mathrm{eV}\left(\mathrm{As}_{40} \mathrm{Se}_{60}\right)$ as the $\mathrm{Se}$ content increases from 15 to $60 \mathrm{~mol} \%$. Figure 5 shows S $2 p$ and Se $3 p$ spectra. The S $2 p$ peaks are located around 162 $163 \mathrm{eV}$, with a separation of $1.18 \mathrm{eV}$ between $\mathrm{S} 2 p_{3 / 2}$ and $\mathrm{S} 2 p_{1 / 2} ; \mathrm{Se} 3 p$ peaks are located in the range of $160-166 \mathrm{eV}$, with a separation of $5.75 \mathrm{eV}$ between $\operatorname{Se} 3 p_{3 / 2}$ and $\operatorname{Se} 3 p_{1 / 2}$. As can be seen for the ternary chalcogenide glasses, $\operatorname{Se} 3 p_{3 / 2}$ overlaps with the two peaks of $\mathrm{S} 2 p$. The increase of relative intensity of $\mathrm{S} 2 p$ peaks with increasing $\mathrm{S}$ content is clearly visible. Figure 6 represents the valence-band XPS spectra of $\mathrm{As}_{40} \mathrm{~S}_{60-x} \mathrm{Se}_{x}$ glasses. For comparison, the valence band of elemental Se sample is also shown. There is a relatively small variation of the valence-band structure among the different $\mathrm{As}_{40} \mathrm{~S}_{60-x} \mathrm{Se}_{x}$ glasses. It can be noticed that the band at $5.5 \mathrm{eV}$ remains featureless. A band in this region is characteristic of elemental Se. 


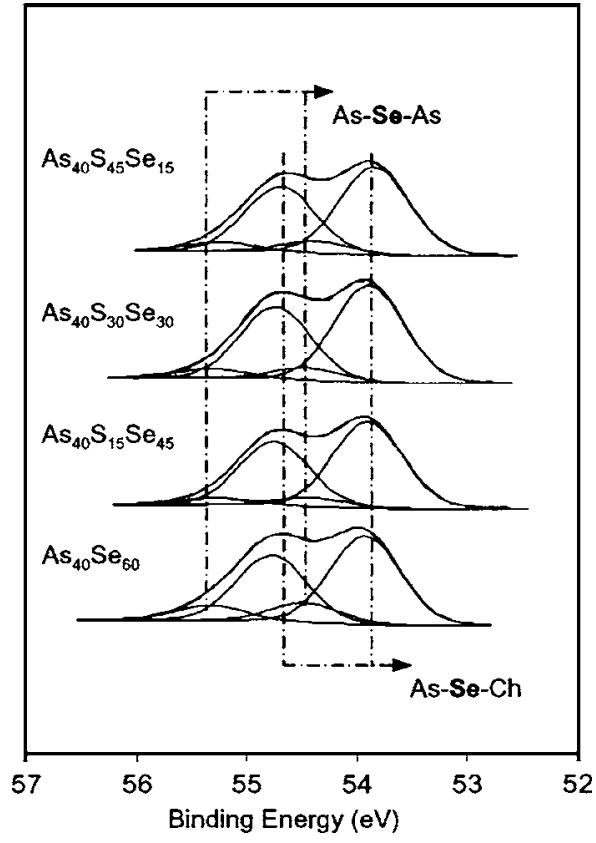

FIG. 4. XPS Se3d spectra and deconvolution of bulk chalcogenide glasses $\mathrm{As}_{40} \mathrm{~S}_{60-x} \mathrm{Se}_{x}$.

\section{B. $\mathrm{As}_{24} \mathrm{~S}_{76-x} \mathrm{Se}_{x}$ glasses $(x=0,19,38,57,76)$}

\section{Raman results}

Figure 7 depicts the Raman spectra of bulk chalcogenrich glasses $\mathrm{As}_{24} \mathrm{~S}_{76-x} \mathrm{Se}_{x}(x=0,19,38,57,76)$, which correspond to compositions $6,7,8,9$, and 10 in Fig. 1. The peak-fitting results are also shown in the same figure, and will be discussed later.

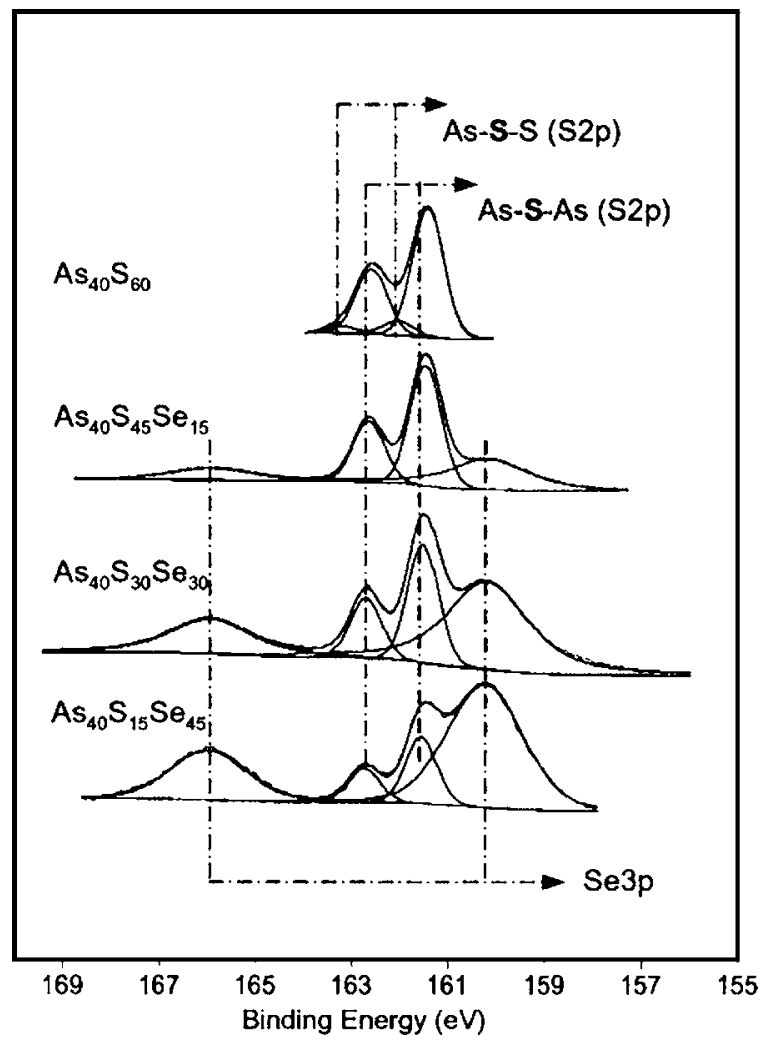

FIG. 5. XPS S $2 p$ and Se $3 p$ spectra and deconvolution of bulk chalcogenide glasses $\mathrm{As}_{40} \mathrm{~S}_{60-x} \mathrm{Se}_{x}$.

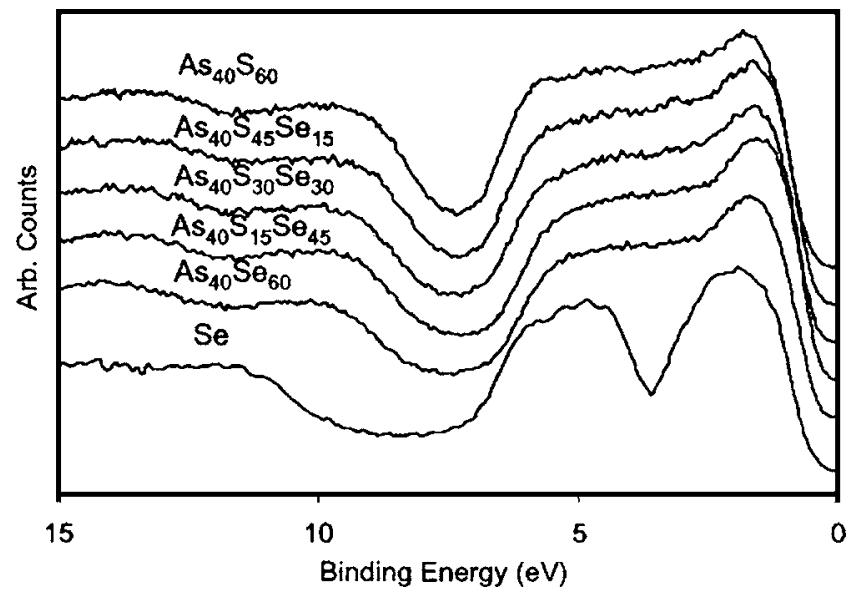

FIG. 6. Valence bands in $\mathrm{As}_{40} \mathrm{~S}_{60-x} \mathrm{Se}_{x}$ bulk chalcogenide glasses.

As the stochiometric ternary compounds in $\mathrm{As}_{40} \mathrm{~S}_{60-x} \mathrm{Se}_{x}$ series, there are two broad bands located at similar positions in the Raman spectra for $\mathrm{As}_{24} \mathrm{~S}_{76-x} \mathrm{Se}_{x}$, associated with As-S and As-Se vibrations. However, differences can clearly be seen between the two systems. Firstly, a new band appears at the high-frequency range $\left(420-520 \mathrm{~cm}^{-1}\right)$ for S-rich $\mathrm{As}_{24} \mathrm{~S}_{76-x} \mathrm{Se}_{x}$, which is accompanied by the rising background in the low-frequency range (below $280 \mathrm{~cm}^{-1}$ ). Secondly, in As-Se-related range $\left(200-280 \mathrm{~cm}^{-1}\right)$, there is an emergency of the $257-\mathrm{cm}^{-1}$ peak in every Se-containing $\mathrm{As}_{24} \mathrm{~S}_{76-x} \mathrm{Se}_{x}$ glass. In all the Se-containing $\mathrm{As}_{24} \mathrm{~S}_{76-x} \mathrm{Se}_{x}$ glasses, a noticeable change in the broad band between 200 and $280 \mathrm{~cm}^{-1}$ with decreasing Se content is the decrease of the intensity of the band at $227 \mathrm{~cm}^{-1}$, which is characteristic of the As-Se vibration in $\mathrm{AsSe}_{3}$ pyramids.

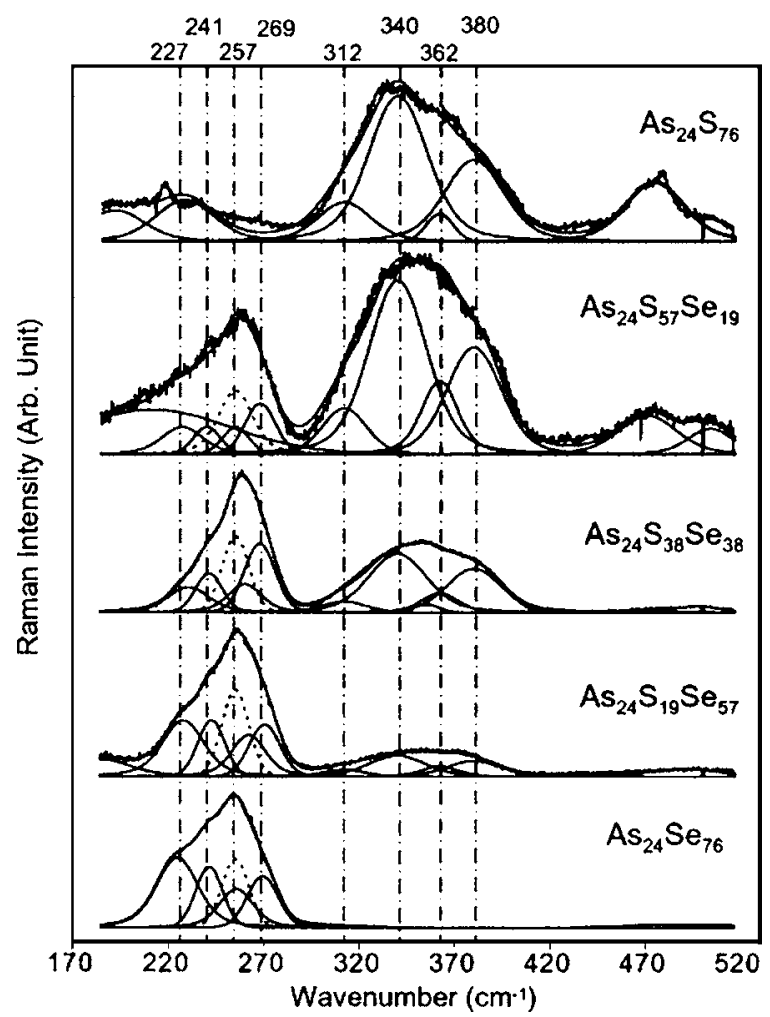

FIG. 7. Raman spectra and deconvolution of bulk chalcogenide glasses $\mathrm{As}_{24} \mathrm{~S}_{76-x} \mathrm{Se}_{x}$. 


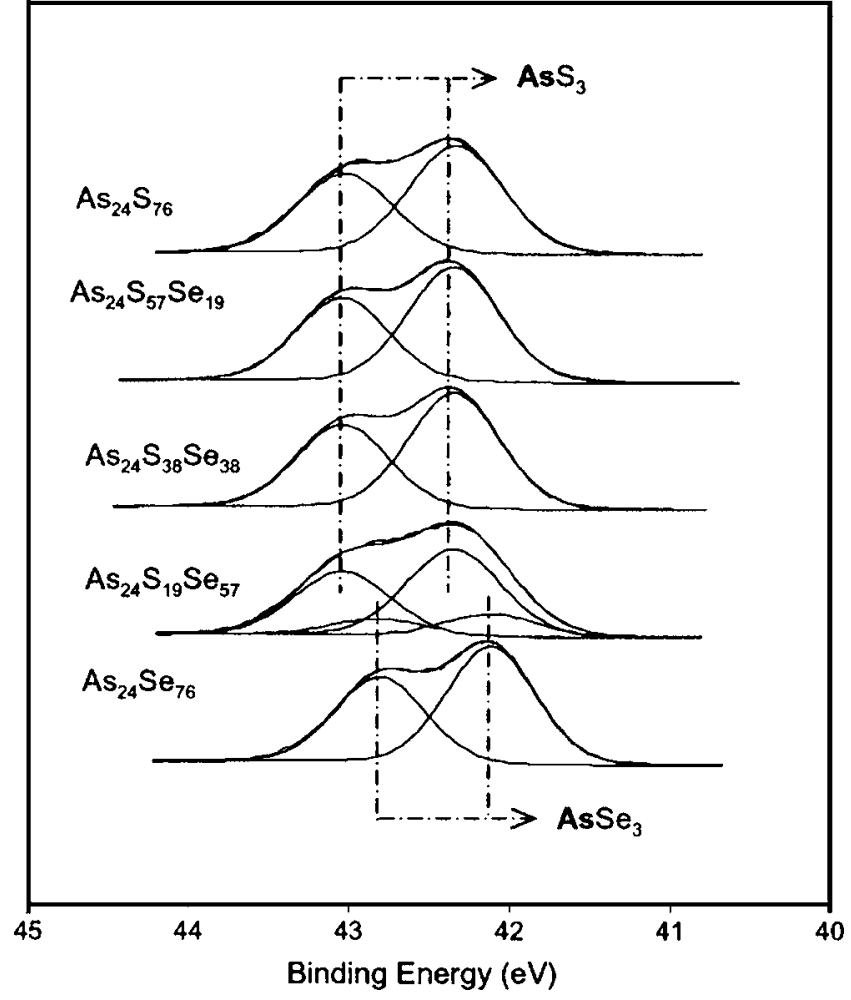

FIG. 8. XPS As3d spectra and deconvolution of bulk chalcogenide glasses $\mathrm{As}_{24} \mathrm{~S}_{76-x} \mathrm{Se}_{x}$.

For $\mathrm{As}_{24} \mathrm{~S}_{76}$, while the $340-\mathrm{cm}^{-1}$ band (As-S in $\mathrm{AsS}_{3}$ ) remains strong, the $312-\mathrm{cm}^{-1}$ shoulder is substantially weaker as compared with $\mathrm{As}_{40} \mathrm{~S}_{60}$. Also a shoulder at $365 \mathrm{~cm}^{-1}$ appears, which has been assigned to the $\mathrm{As}_{2} \mathrm{~S}_{5}$ structure, and interaction occurs between $\mathrm{AsS}_{3}$ pyramids with S-S chains. ${ }^{73,74}$ Meanwhile, the two bands at 219 and $474 \mathrm{~cm}^{-1}$, associated with $\mathrm{S}_{8}$ rings, ${ }^{75,18}$ are also observed. In addition to those peaks, a weak peak at $494 \mathrm{~cm}^{-1}$ and a shoulder at $465 \mathrm{~cm}^{-1}$ also are observed; the former is associated with $\mathrm{S}-\mathrm{S}$ chains ${ }^{18}$ and the latter has been suggested to be an indication of a terminal, or nonbridging, As-S bond, such as in $\mathrm{AsS}_{3}=\mathrm{S} .^{73}$ In $\mathrm{As}_{24} \mathrm{~S}_{57} \mathrm{Se}_{19}$, one can observe a slight shift of the As-S band, and the $\mathrm{S}-\mathrm{S}$ chain $\left(494 \mathrm{~cm}^{-1}\right)$ and $S$ ringlike $\left(474 \mathrm{~cm}^{-1}\right)$ structures are still observable.

\section{XPS result}

XPS results of $\mathrm{As} 3 d, \mathrm{Se} 3 d, \mathrm{~S} 2 p$ and $\mathrm{Se} 3 p$, and the valence-band spectra of $\mathrm{As}_{24} \mathrm{~S}_{76-x} \mathrm{Se}_{x}$ bulk glasses are plotted in Figs. 8-11, respectively. The corresponding peak-fitting results are also shown in the same figures, and will be discussed later.

From the As3d spectra (Fig. 8), we observe that in $\mathrm{As}_{24} \mathrm{~S}_{76-x} \mathrm{Se}_{x}$, with Se increasing from 0 to $76 \mathrm{~mol} \%$, the binding energy of As3 $d_{5 / 2}$ decreases from $42.34\left(\mathrm{As}_{24} \mathrm{~S}_{76}\right)$ to $42.12 \mathrm{eV}\left(\mathrm{As}_{24} \mathrm{Se}_{76}\right)$. From $\mathrm{As}_{24} \mathrm{~S}_{76}$ to $\mathrm{As}_{24} \mathrm{~S}_{38} \mathrm{Se}_{38}$, the binding energy shows very little change; the variation of binding energy is more clearly observable in the Se-rich compositions. The As3d peak of $\mathrm{As}_{24} \mathrm{~S}_{19} \mathrm{Se}_{57}$ is relatively broad, indicative of different As environments. Figure 9 shows a small decrease in the binding energy of $\operatorname{Se} 3 d_{5 / 2}$ peak from 54.55 to $54.37 \mathrm{eV}$ as the $\mathrm{S}$ content decreases; the $\mathrm{Se} 3 d$ peaks

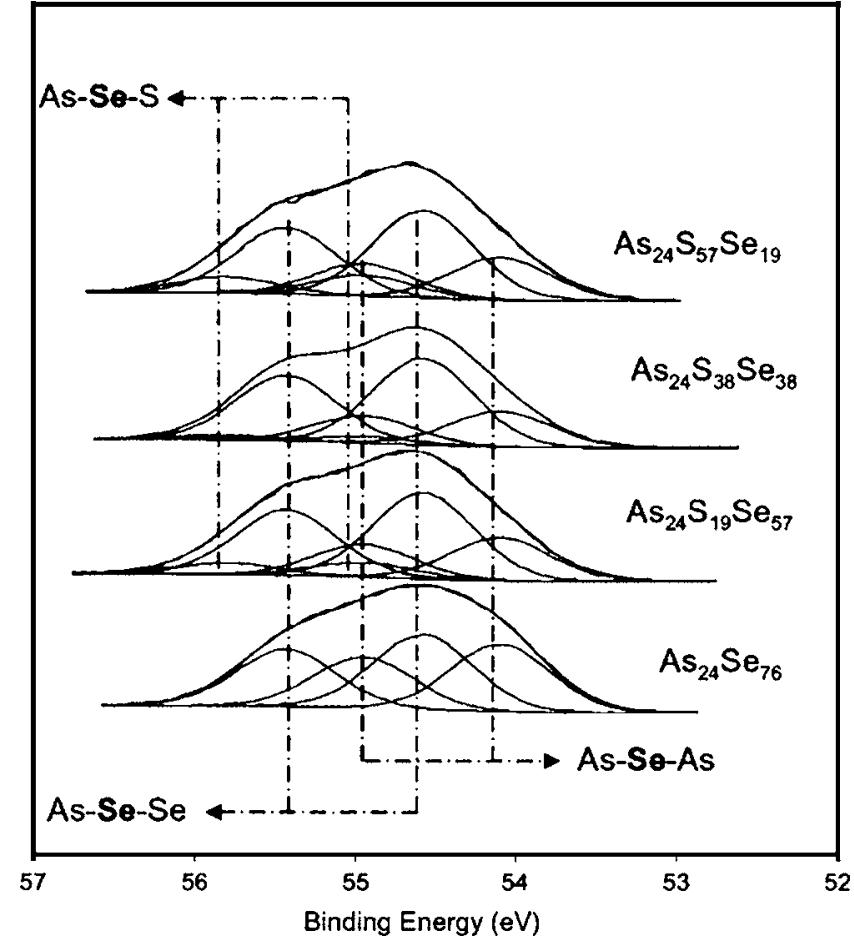

FIG. 9. XPS Se3d spectra and deconvolution of bulk chalcogenide glasses $\mathrm{As}_{24} \mathrm{~S}_{76-x} \mathrm{Se}_{x}$.

for $\mathrm{As}_{24} \mathrm{~S}_{76-x} \mathrm{Se}_{x}$ glasses are wider compared with $\mathrm{As}_{40} \mathrm{~S}_{60-x} \mathrm{Se}_{x}$ glasses, and the $3 d$ split is less visible. Both indicate more than one $\mathrm{Se}$ environment in $\mathrm{As}_{24} \mathrm{~S}_{76-x} \mathrm{Se}_{x}$ glasses. Figure 10 shows the $\mathrm{S} 2 p$ and $\mathrm{Se} 3 p$ peaks of $\mathrm{As}_{24} \mathrm{~S}_{76-x} \mathrm{Se}_{x}$ glasses. Comparing the $\mathrm{S} 2 p$ peaks of these

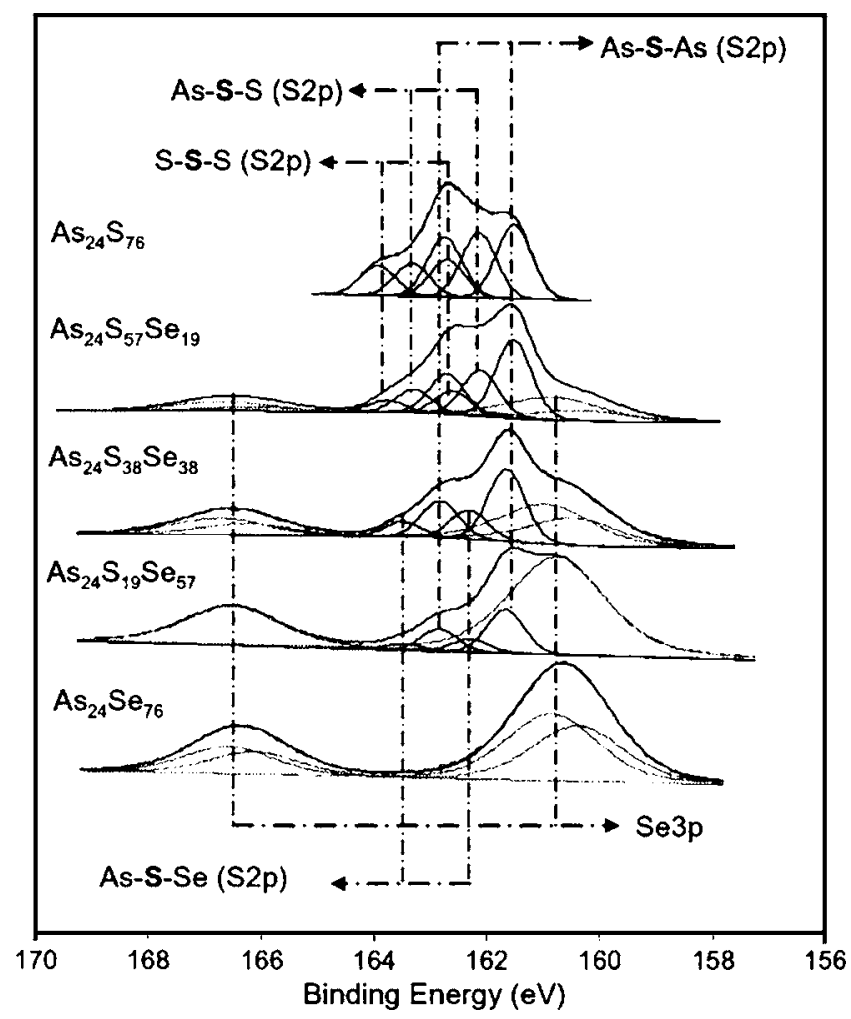

FIG. 10. XPS S $2 p$ and Se $3 p$ spectra and deconvolution of bulk chalcogenide glasses $\mathrm{As}_{24} \mathrm{~S}_{76-x} \mathrm{Se}_{x}$. 


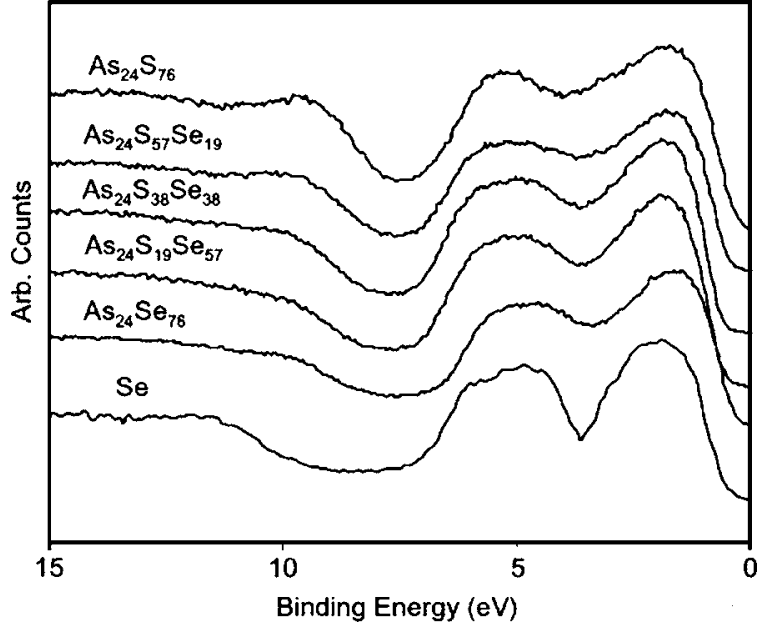

FIG. 11. Valence bands in $\mathrm{As}_{24} \mathrm{~S}_{76-x} \mathrm{Se}_{x}$ bulk chalcogenide glasses.

glasses with that of $\mathrm{As}_{40} \mathrm{~S}_{60-x} \mathrm{Se}_{x}$, it is clear that more than one $\mathrm{S}$ environment is present in the chalcogen-rich glasses. Figure 11 represents the valence-band XPS spectra of $\mathrm{As}_{24} \mathrm{~S}_{x} \mathrm{Se}_{76-x}$ glasses. For comparison, the valence band of elemental Se sample is also shown in Fig. 11. With increasing $\mathrm{Se}$, the band located at $5.5 \mathrm{eV}$ becomes more distinct, which are characteristic of elemental Se.

\section{EXAFS results}

The normalized EXAFS spectra of the arsenic $K$ edges for glass compositions in the series $\mathrm{As}_{24} \mathrm{~S}_{76-x} \mathrm{Se}_{x}$ ( $x=19,38$, 57) are shown in Fig. 12(a). The phase-corrected Fourier transformation of arsenic $K$-edge EXAFS spectra for all glass spectra are shown in Fig. 12(b).

For the three compositions measured, the arsenic $K$-edge EXAFS spectra showed a single peak. For the constant arsenic samples, replacing $\mathrm{S}$ by Se shifts the peak maximum in the radial distribution function to higher values, which indicates a lengthening of bonds between As and its neighbor. The peak maximum, corresponding to the average bond length, was almost the same for $\mathrm{As}_{24} \mathrm{~S}_{57} \mathrm{Se}_{19}(2.3 \AA)$ and $\mathrm{As}_{24} \mathrm{~S}_{38} \mathrm{Se}_{38}(2.29 \AA)$, but a bigger change is noticed in $\mathrm{As}_{24} \mathrm{~S}_{19} \mathrm{Se}_{57}(2.34 \AA)$. The corrected and fitted data results using the EXAFSPAK XAS software are shown in Table III.

\section{DISCUSSION}

\section{A. $A s_{40} S_{60-x} \mathrm{Se}_{x}$ glasses $(x=0,15,30,45,60)$ \\ 1. Raman results}

Broad bands at $200-280$ and $280-400 \mathrm{~cm}^{-1}$ have been observed in binary selenide $\mathrm{As}_{2} \mathrm{Se}_{3}$ and sulfide $\mathrm{As}_{2} \mathrm{~S}_{3}$, re-

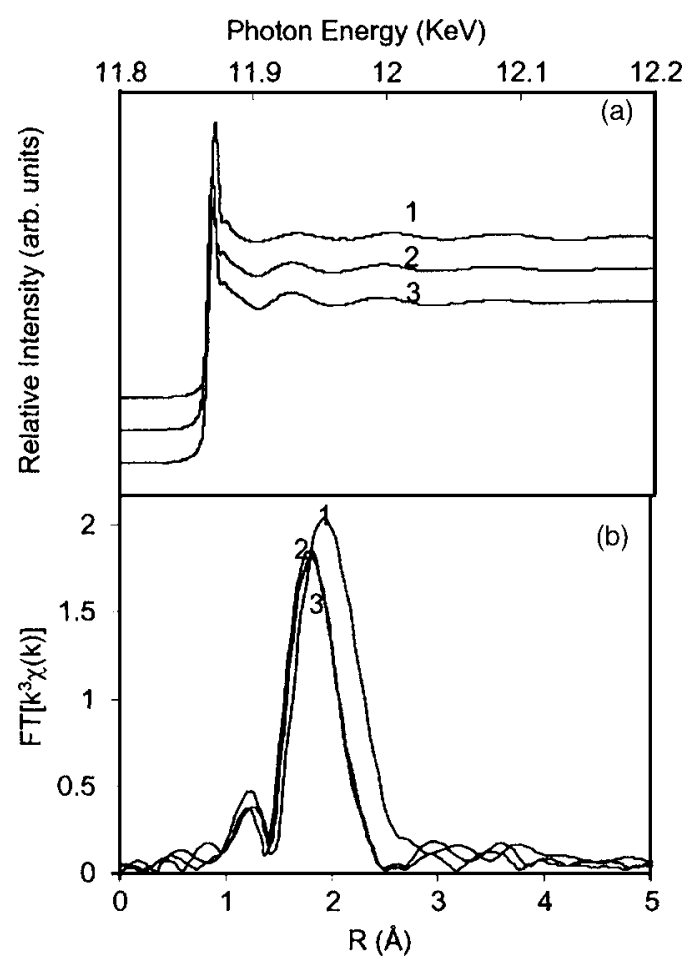

FIG. 12. (a) Arsenic $K$-edge EXAFS spectra and (b) the Fourier-transformed arsenic $K$-edge EXAFS for $\mathrm{As}_{24} \mathrm{~S}_{76-x} \mathrm{Se}_{x}$. Three sample compositions examined include [Fig. 1 composition number]: (1) $\mathrm{As}_{24} \mathrm{~S}_{19} \mathrm{Se}_{57}$ [9], (2) $\mathrm{As}_{24} \mathrm{~S}_{38} \mathrm{Se}_{38}$ [8], and (3) $\mathrm{As}_{24} \mathrm{~S}_{57} \mathrm{Se}_{19}$ [7].

spectively. The former is attributed to As-Se-As stretching vibration in the $\mathrm{AsSe}_{3}$ pyramids and the latter to As-S-As in $\mathrm{AsS}_{3}$ pyramids. ${ }^{18,23,73,76-86}$ The relative intensity change of these two broad bands (shown in Fig. 2) is consistent with the change of the relative ratio of $\mathrm{Se} / \mathrm{S}$ in these glasses.

Similar peak shifts in the As-Se-related band (200-280 $\left.\mathrm{cm}^{-1}\right)$ were also observed by Frietas et al. ${ }^{87}$ and Onari et $a l^{88}$ The peak shift and the polarization study in the reference suggested that more than one species of vibration is contributing to the band at $\left(200-280 \mathrm{~cm}^{-1}\right)$. There are four possible $\mathrm{AsS}_{3-n} \mathrm{Se}_{n}$ pyramids with $n=0,1,2$, 3. Among them, three pyramids can contribute to As-Se vibration, $\mathrm{AsS}_{2} \mathrm{Se}, \mathrm{AsSSe}_{2}$, and $\mathrm{AsSe}_{3}$. With increasing Se in the pyramids, the mode mass would be expected to be somewhat bigger and, consequently, the frequency would be expected to be lower. This is consistent with the observed frequency shift of the $200-280-\mathrm{cm}^{-1}$ band.

According to Wagner et al. ${ }^{74}$ the two shoulders around 312 and $380 \mathrm{~cm}^{-1}$ in the As-S range are due to interactions among and between the $\mathrm{AsS}_{3}$ pyramids. With increasing Se,

TABLE III. EXAFS data-fitting results: $N$-neighboring atom number; $R$ - the distance from neighboring atom to the absorbing atom; $\sigma$-the standard deviation of the interatomic distance, and $\Delta E_{0}$-correction for estimated edge step $E_{0}$.

\begin{tabular}{lllllll}
\hline \hline Composition & Fitting & Shell & $N$ & $\begin{array}{c}R \\
(\AA)\end{array}$ & $\begin{array}{c}\sigma^{2} \\
\left(\AA^{2}\right)\end{array}$ & $\begin{array}{c}\Delta E_{0} \\
(\mathrm{eV})\end{array}$ \\
\hline $\mathrm{As}_{24} \mathrm{~S}_{38} \mathrm{Se}_{38}$ & With S & As-S & 3.1 & 2.29 & 0.0035 & -7.4 \\
$\mathrm{As}_{24} \mathrm{~S}_{57} \mathrm{Se}_{19}$ & With S & As-S & 3.31 & 2.3 & 0.004 & -5.916 \\
$\mathrm{As}_{24} \mathrm{~S}_{19} \mathrm{Se}_{57}$ & Add Se & As-S & 1.92 & 2.32 & 0.0004 & 3.679 \\
& & As-Se & 2 & 2.49 & 0.011 & 3.679 \\
\hline \hline
\end{tabular}


there are fewer $\mathrm{AsS}_{3}$ pyramids in the glasses, and the intensity of interaction-related vibration should be reduced. This is consistent with our observation. A similar reason could account for the disappearance of two shoulders in As-Serelated frequency range.

Figure 2 shows the peak deconvolution of the Raman results of $\mathrm{As}_{40} \mathrm{~S}_{60-x} \mathrm{Se}_{x}$ glasses. In the As-Se-related peak range, the main Raman bands are assigned to the As-Se vibration of the $\mathrm{AsSe}_{3}$ and $\mathrm{AsS}_{3-n} \mathrm{Se}_{n}$ pyramids (227, 241, and $\left.257 \mathrm{~cm}^{-1}\right)$ and their interactions $\left(269 \mathrm{~cm}^{-1}\right)$; and in As-Srelated range, the deconvoluted Raman peaks are assigned to the As-S vibration of the $\mathrm{AsS}_{3}$ and $\mathrm{AsS}_{3-n} \mathrm{Se}_{n}$ pyramids (340 and $362 \mathrm{~cm}^{-1}$ ) and their interactions (312 and $\left.380 \mathrm{~cm}^{-1}\right)$. This is consistent with the multiple vibrations found in crystalline $\mathrm{As}_{2} \mathrm{Se}_{3}, \mathrm{As}_{2} \mathrm{~S}_{3}$, and $\mathrm{As}_{2} \mathrm{SSe}_{2} \cdot{ }^{87,89}$ However, we must also point out that the peaks at 241 and $257 \mathrm{~cm}^{-1}$ are also the main features in pure Se glasses and they have been assigned for Se-Se vibration in chain and ring fragments, respectively. ${ }^{90}$ Likewise, the peak at $362 \mathrm{~cm}^{-1}$ corresponds to the main feature of $\mathrm{As}_{4} \mathrm{~S}_{4}$ molecules. ${ }^{91}$ We do not consider that the peak components around 241 and $257 \mathrm{~cm}^{-1}$ are evidence of $\mathrm{Se}-\mathrm{Se}$ bonds in bulk $\mathrm{As}_{40} \mathrm{~S}_{60-x} \mathrm{Se}_{x}$ glasses. To our knowledge, no previous study supports the expectation for a large quantity of $\mathrm{Se}-\mathrm{Se}$ homopolar bonds in bulk $\mathrm{As}_{40} \mathrm{~S}_{60-x} \mathrm{Se}_{x}$ glasses, although it is possible that a limited amount of Se-Se "wrong" bonds exist in stochiometric composition, which is confirmed by XPS. As for the $362-\mathrm{cm}^{-1}$ peak component, which has been previously associated with the $\mathrm{As}_{4} \mathrm{~S}_{4}$ molecular clusters in $\mathrm{As}_{2} \mathrm{~S}_{3}$ films ${ }^{27,91}$ and As-rich $\mathrm{As}_{x} \mathrm{~S}_{1-x}$ bulk glasses, ${ }^{79}$ the existence of those peak components does not necessarily indicate the presence of $\mathrm{As}_{4} \mathrm{~S}_{4}$ molecules in $\mathrm{As}_{40} \mathrm{~S}_{60-x} \mathrm{Se}_{x}$ bulk glasses. Actually, the nuclear quadrupole resonance (NQR) study in glassy $\mathrm{As}_{2} \mathrm{Se}_{3}$ and $\mathrm{As}_{2} \mathrm{~S}_{3}$ systems $^{92}$ of Treacy et al. shows that there is no $\mathrm{As}_{4} \mathrm{Ch}_{4}(\mathrm{Ch}=\mathrm{S}, \mathrm{Se})$ molecule found in bulk $\mathrm{As}_{2} \mathrm{Se}_{3}$ and $\mathrm{As}_{2} \mathrm{~S}_{3}$, while they are the main components in as-deposited films, as shown by previous studies. ${ }^{27}$

\section{XPS results}

Figures 3, 4, and 5 show the peak deconvolution of the XPS results of As $3 d, \mathrm{Se} 3 d$, and $\mathrm{S} 2 p$ for the $\mathrm{As}_{40} \mathrm{~S}_{60-x} \mathrm{Se}_{x}$ series. According to the As3d peaking-fitting results of $\mathrm{As}_{40} \mathrm{~S}_{60-x} \mathrm{Se}_{x}$ (Fig. 3), the As atoms exist in $\mathrm{AsCh}_{3}$ units $(\mathrm{Ch}=\mathrm{S}, \mathrm{Se})$. The As3d peak is deconvoluted into two components, $\mathrm{AsS}_{3}\left(\mathrm{As}_{3} d_{5 / 2}\right.$ at $\left.42.34 \mathrm{eV}\right)$ and $\mathrm{AsSe}_{3}\left(\mathrm{As} 3 d_{5 / 2}\right.$ at $42.11 \mathrm{eV})$. Note that the complete representation of all possible mixed pyramidal units is using $\mathrm{As}_{2} \mathrm{~S}_{3}, \mathrm{As}_{2} \mathrm{~S}_{2} \mathrm{Se}$, $\mathrm{As}_{2} \mathrm{SSe}_{2}$, and $\mathrm{As}_{2} \mathrm{Se}_{3}$ components to deconvolute the As3d peaks into four components, but the reference data on $\mathrm{As}_{2} \mathrm{~S}_{2} \mathrm{Se}$ and $\mathrm{As}_{2} \mathrm{SSe}_{2}$ are not currently available. Here we use two reference environments to show the As environment transition. No evidence of As-As (at a lower binding energy than that of $\mathrm{AsSe}_{3}$ ) can be found based on peak-fitting results.

Figure 5 shows the $\mathrm{S} 2 p$ peak deconvolution of $\mathrm{As}_{40} \mathrm{~S}_{60-x} \mathrm{Se}_{x}$ glasses. While most of the $\mathrm{S}$ would form As$\mathbf{S}-$ As bonds, it is possible for some $\mathrm{S}$ to form wrong bonds As-S-S-As. From Raman, we observed low but measurable signal for $\mathrm{S}-\mathrm{S}$ bonds in $\mathrm{As}_{2} \mathrm{~S}_{3}$ bulk glasses. XPS data analysis of $\mathrm{As}_{40} \mathrm{~S}_{60-x} \mathrm{Se}_{x}$ glasses also show two $\mathrm{S}$ environments in $\mathrm{As}_{2} \mathrm{~S}_{3}$, one as the dominant As-S-As, the other as As-S-S. In the Se-containing $\mathrm{As}_{40} \mathrm{~S}_{60-x} \mathrm{Se}_{x}$ glasses (samples 2-5 in Fig. 1), only one $S$ environment is found. It is assigned to As-S-As species, and a small $(\sim 0.05 \mathrm{eV})$ yet systematic increase is found in $\mathrm{S}$ binding energy when the Se content increases. We believe this small change of S binding energy is due to the systematic change of As-S-As bonds, associated with the introduction of Se into the $\mathrm{As}_{2} \mathrm{~S}_{3}$ network and the corresponding occurrence of mixed pyramidal units. It might be expected that in such mixed units As-S bonds are stretched with Se addition (bond length longer than that in $\mathrm{As}_{2} \mathrm{~S}_{3}$ ), and $\mathrm{As}-\mathrm{Se}$ bonds are contracted with $\mathrm{S}$ addition (bond length shorter than that of $\mathrm{As}_{2} \mathrm{Se}_{3}$ ), so the $\mathrm{S}$ binding energy in a mixed pyramidal unit would be expected to be slightly higher than in an $\mathrm{AsS}_{3}$ unit. Similarly, the Se binding energy in mixed pyramidal units should be slightly lower than in the $\mathrm{AsSe}_{3}$ unit, which is observed in $\mathrm{Se} 3 d$ peak deconvolution results (Fig. 4), as well as a small yet systematic decrease of the Se binding energy of the As-Se-As environment, due to the same reason.

As with S, most Se form As-Se-As bonds. The difference between $S$ and Se environments is that while $S$ is found in two environments only in $\mathrm{As}_{2} \mathrm{~S}_{3}$ composition, Se is found in two environments in all stochiometric compositions. While most of Se is assigned to Se in pyramidal unit As-SeAs, the second environment is explained in terms of AsSe-Ch (As-Se-S-As or As-Se-Se, depending on the composition), present in low concentrations. Because there is no evidence of the existence of As-S-Se-As in S2p deconvolution results, we assume that $\mathrm{As}-\mathrm{Se}-\mathrm{Ch}$ is mainly $\mathrm{As}-\mathrm{Se}-\mathrm{Se}$ bonds in the stochiometric series.

It is not surprising to see a limited amount of $\mathrm{Ch}-\mathrm{Ch}$ bonds in stochiometric As-S-Se glasses, due to the disordered nature of the glass system. The observation that when $\mathrm{Se}$ is present in the glass system, $\mathrm{S}$ stays in pyramidal units and $\mathrm{Se}$ forms $\mathrm{Se}-\mathrm{Se}$ bonds is well consistent with our earlier conclusion. $^{4}$

However, there is one concern about the As3d deconvolution results: one might expect As-As bonds corresponding to the $\mathrm{Ch}-\mathrm{Ch}$ bonds in the stochiometric compositions, most likely in structures such as $\mathrm{As}-\mathrm{AsCh}_{2}$, but we do not find such evidence in As3d deconvolution results. One possible explanation is that the environment change for As from $\mathrm{AsCh}_{3}$ to $\mathrm{As}-\mathrm{AsCh}_{2}$ is for one third of the neighbors, but for the $\mathrm{Ch}$ a change from $\mathrm{As}-\mathrm{Ch}-\mathrm{As}$ to $\mathrm{As}-\mathrm{Ch}-\mathrm{Ch}$ is for one half of the environments, so the binding energy change is less noticeable. An EDS composition study on these glasses is ongoing to verify the composition of these glasses, again to see if there is any possible change in the glass meltingquenching process that would cause these glasses to be slightly chalcogen-rich. As mentioned in the sample preparation, the compositions of these samples were verified after glass formation to have an error around $1 \%$. 


\section{B. $A s_{24} S_{76-x} \mathrm{Se}_{x}$ glasses $(x=0,19,38,57,76)$ 1. Raman results}

In chalcogen-rich binary systems $\mathrm{As}_{x} \mathrm{Ch}_{1-x}(\mathrm{Ch}=\mathrm{S}, \mathrm{Se}$, and $x<0.4)$, the molecular structure has been widely accepted as a random network of chalcogen chain fragments cross-linked by pyramidal $\mathrm{AsCh}_{3 / 2}$ units. ${ }^{18,19}$

According to previous Raman studies, ${ }^{76,93}$ the Ramanactive vibrations at $345 \mathrm{~cm}^{-1}$ observed in $\mathrm{As}_{2} \mathrm{~S}_{3}$ and at $230 \mathrm{~cm}^{-1}$ observed in $\mathrm{As}_{2} \mathrm{Se}_{3}$ are due to an intermolecular mode resulting from an antisymmetric As-S-As and AsSe-As stretching vibration, respectively. Two bands at 434 and $474 \mathrm{~cm}^{-1}$ have been reported in liquid sulfur as bond stretching of $\mathrm{S}_{8}$ rings. ${ }^{94}$ The band at around $255 \mathrm{~cm}^{-1}$ is attributed to $\mathrm{Se}-\mathrm{Se}$ bond vibrations. ${ }^{95,4}$ In pure amorphous Se, an intense band occurs at $250 \mathrm{~cm}^{-1}$ with a small shoulder at $235 \mathrm{~cm}^{-1}$. The band at $250 \mathrm{~cm}^{-1}$ has been attributed by Lucovsky $^{90}$ to stretching vibrations of "meandering" Se chains, while the small shoulder at $235 \mathrm{~cm}^{-1}$ (typical of crystalline trigonal Se) has been associated with helical chains.

Figure 7 shows the peak deconvolution of the Raman results for $\mathrm{As}_{24} \mathrm{~S}_{76-x} \mathrm{Se}_{x}$ glasses, using the same peak components. Comparing the Raman results for the chalcogen-rich glasses with the stochiometric ternary compounds $\mathrm{As}_{40} \mathrm{~S}_{60-x} \mathrm{Se}_{x}$, it is evident that the chalcogen-chalcogen bonds, such as $\mathrm{S}-\mathrm{S}$ and $\mathrm{Se}-\mathrm{Se}$ or $\mathrm{S}-\mathrm{Se}$, exist in the chalcogen-rich As-S-Se glass system.

The evidences of the $\mathrm{S}-\mathrm{S}$ chain $\left(494 \mathrm{~cm}^{-1}\right)$ and $\mathrm{S}$ ringlike $\left(474 \mathrm{~cm}^{-1}\right)$ structures are clearly visible in the Raman spectra of $\mathrm{As}_{24} \mathrm{~S}_{76}$ and $\mathrm{As}_{24} \mathrm{~S}_{57} \mathrm{Se}_{19}$, while the evidence of $\mathrm{Se}-\mathrm{Se}$ bonds can be observed in Se-containing glasses. For instance, in $\mathrm{As}_{24} \mathrm{Se}_{76}$, the peak component around $257 \mathrm{~cm}^{-1}$ has been shown in two peaks: one is assigned to $\mathrm{AsS}_{3-n} \mathrm{Se}_{n}$ pyramids (shown in solid line), and its intensity is chosen so that its relative intensity to the $\operatorname{AsSe}_{3}\left(227 \mathrm{~cm}^{-1}\right)$ component is the same with that in $\mathrm{As}_{40} \mathrm{Se}_{60}$; and the other is shown in dashed line, which is assigned to Se-Se vibration. Similarly, the $\mathrm{Se}-\mathrm{Se}$ vibration is evident in all $\mathrm{As}_{24} \mathrm{~S}_{76-x} \mathrm{Se}_{x}$ ternary glasses.

While the formation of $\mathrm{Se}-\mathrm{Se}$ is evident from the 257$\mathrm{cm}^{-1}$ vibration, and $\mathrm{S}-\mathrm{S}$ from the $474-$ and $494-\mathrm{cm}^{-1}$ vibration, the $\mathrm{S}-\mathrm{Se}$ bond $^{96}$ is indicated by the vibration at $355 \mathrm{~cm}^{-1}$, which is used in $\mathrm{As}_{24} \mathrm{~S}_{38} \mathrm{Se}_{38}$ (only) as a peak component for peak fitting.

It can be seen that the $\mathrm{S}-\mathrm{S}$ bonds reduce rapidly with a decrease of $\mathrm{S}$ content, and disappear at $\mathrm{S}=38$ at. \% $\mathrm{Se}-\mathrm{Se}$ bonds reduce more slowly in content with a similar decrease in Se content; for example, there are still a substantial number at $\mathrm{Se}=38$ at. \%. The relative concentration difference between Se-Se and $\mathrm{S}-\mathrm{S}$ bonds in $\mathrm{As}_{24} \mathrm{~S}_{38} \mathrm{Se}_{38}$ is striking; we can confidently suggest that it is the $\mathrm{S}$ atom which remains in the pyramidal $\mathrm{AsCh}_{3}$ units, while the Se tends to form homopolar Se-Se or heteropolar S-Se bonds.

In $\mathrm{As}_{24} \mathrm{~S}_{76}$, two bands at 365 and $465 \mathrm{~cm}^{-1}$ are observed, both indicative of the $\mathrm{As}_{2} \mathrm{~S}_{5}$ species present in the structure. With increasing Se content, there is a slight shift of the peak of the As-S-related broad band toward higher frequencies. This observation may be related to the contribution of S-Se bands, but we also observe a similar trend in the stochiomet- ric system (to a lesser extent), whose reason is not yet clear. The peak position shift (towards higher frequencies) of AsSe-related bonds with increasing $\mathrm{S}$ content can be explained in terms of a decrease in the effective mass of the vibrational mode.

\section{XPS results}

Figures 8, 9, and 10 show the peak deconvolution of the XPS results of As3d,Se3d, and $\mathrm{S} 2 p$ for the $\mathrm{As}_{24} \mathrm{~S}_{76-x} \mathrm{Se}_{x}$ series. In Fig. 8, As3d peaks are deconvolved into two components, $\mathrm{AsS}_{3}$ and $\mathrm{AsSe}_{3}$. In chalcogen-rich glasses, there is very little chance of forming As-As bonds, so we can safely assume that in these glasses As atoms are found in (pure or mixed) $\mathrm{AsCh}_{3}$ pyramidal units. Fitting results show that As species mainly remain connected with $\mathrm{S}$ to form $\mathrm{AsS}_{3}$ pyramidal units, and Se joins the unit to form mixed pyramidal only when there is no sufficient $\mathrm{S}$ (at $\mathrm{As}_{24} \mathrm{~S}_{19} \mathrm{Se}_{57}$ ).

According to $\mathrm{S} 2 p$ and $\mathrm{Se} 3 p$ fitting results (Fig. 10), three $\mathrm{S}$ environments are found in $\mathrm{As}_{24} \mathrm{~S}_{76}$, which are assigned to As-S-As, As-S-S-As, and As-S-S-S-As. For $\mathrm{As}_{24} \mathrm{~S}_{57} \mathrm{Se}_{19}$, there are also three $\mathrm{S}$ environments, As-S-As, As-S-S-As, and As-S-S-Se-As. In $\mathrm{As}_{24} \mathrm{~S}_{38} \mathrm{Se}_{38}$, two $\mathrm{S}$ environments are found, As-S-As and As-S-Se; similar is the case for $\mathrm{As}_{24} \mathrm{~S}_{19} \mathrm{Se}_{57}$. In chalcogen-rich environments, As-Ch-ChAs(Ch)-links can have many different combinations and link orders, it is possible that there are more than one species around certain experimentally distinct binding energy values. The fitting results clearly show that there are $\mathrm{Ch}-\mathrm{Ch}$ bonds in the chalcogen-rich composition, and Se has a bigger tendency to stay in the chain. Similar to the stochiometric $\mathrm{As}_{40}(\mathrm{~S}, \mathrm{Se})_{60}$ series, the sulfur binding energy in As-S-As is slightly higher in Se-rich composition, which could be due to the same reason for the stochiometric series.

For Se3 $d$ spectra in chalcogen-rich glasses, peak deconvolution results (Fig. 9) show three Se environments, As-SeAs, As-Se-Se, and As-S-Se-Se. It is possible that the binding energy of Se-Se-Se is located very close to that of AsSe-Se, so that it is difficult to differentiate them.

One important observation, while evaluating the valence band structure, is the intensity change of the two bands located at 2.5 and $5.5 \mathrm{eV}$. In the elemental Se valence band, the peak at $5.5 \mathrm{eV}$ is associated with the bonding $p$ band $(4 p)$ and the peak at $2.5 \mathrm{eV}$ with the lone-pair orbital. ${ }^{97}$ These two features in the valence band of $\mathrm{As}_{24} \mathrm{~S}_{x} \mathrm{Se}_{76-x}$ glass indicate that considerable number of Se-Se homopolar bonds exists in chalcogen-rich As-S-Se compositions, consistent with previously discussed Raman results.

A comparison of the $\mathrm{As}_{40} \mathrm{~S}_{60-x} \mathrm{Se}_{x}$ series (stochiometric compositions) and the $\mathrm{As}_{24} \mathrm{~S}_{76-x} \mathrm{Se}_{x}$ series (chalcogen-rich compositions) shows a clear difference around $2.5 \mathrm{eV}$ (the bonding $4 p$ bond), which indicates more Se-Se homopolar bonds in chalcogen-rich compositions and supports previously proposed structural reason related to chalcogen-rich composition having high optical nonlinearities. ${ }^{4}$

\section{EXAFS results}

EXAFS results showed that the average bond length around As was almost the same for $\mathrm{As}_{24} \mathrm{~S}_{57} \mathrm{Se}_{19}(2.3 \AA)$ and 
$\mathrm{As}_{24} \mathrm{~S}_{38} \mathrm{Se}_{38}(2.29 \AA)$, but larger for $\mathrm{As}_{24} \mathrm{~S}_{19} \mathrm{Se}_{57}(2.34 \AA)$. This further indicates that for $\mathrm{As}_{24} \mathrm{~S}_{57} \mathrm{Se}_{19}$ and $\mathrm{As}_{24} \mathrm{~S}_{38} \mathrm{Se}_{38}$, there is only a minimal difference in the As environment, but for $\mathrm{As}_{24} \mathrm{~S}_{19} \mathrm{Se}_{57}$, there is a large change in the bond length. Considering the ideal covalent bond distance, $R_{\mathrm{As}-\mathrm{Se}}(2.38 \AA)$ and $\mathrm{R}_{\mathrm{As}-\mathrm{S}}(2.25 \AA),{ }^{69,70}$ these results suggest that the nearest neighbor of As in S-rich or $\mathrm{S} / \mathrm{Se}=1$ compositions is mainly $\mathrm{S}$, with Se becoming the nearest neighbor only after $\mathrm{S} / \mathrm{Se}$ is less than 1.0. Because our glass samples are chalcogen-rich, the As-As bond is not considered, as its concentration is expected to be negligible.

EXAFS data-fitting results showed that As has a coordination number of 3-4 in chalcogen-rich As-S-Se. S is preferred to be the near neighbors of As when there are plenty $\mathrm{S}$, such as in $\mathrm{As}_{24} \mathrm{~S}_{38} \mathrm{Se}_{38}$ and $\mathrm{As}_{24} \mathrm{Se}_{57} \mathrm{Se}_{19}$. Only when the $\mathrm{S}$ amount is too low to meet the coordination requirement of As will Se also become a nearest neighbor of As (in the case $\left.\mathrm{As}_{24} \mathrm{~S}_{19} \mathrm{Se}_{57}\right)$. This agrees with both XPS and Raman that $\mathrm{S}$ mainly forms $\mathrm{AsS}_{3 / 2}$ units, and Se will stay in the chain, along with any residual $\mathrm{S}$ atoms.

\section{CONCLUSIONS}

(1) Raman bands at $200-280$ and $280-400 \mathrm{~cm}^{-1}$ indicate that in $\mathrm{As}_{40} \mathrm{~S}_{60-x} \mathrm{Se}_{x}$ glasses, the main structures are $\mathrm{AsCh}_{3}$ pyramidal units and the peak shift of As-S-As vibrations provides further evidence for mixed pyramidal units.

(2) XPS results show the gradual change of As environments, which is consistent with the Raman finding of mixed pyramidal units.

(3) XPS data also show that there are some, although in limited amount, chalcogen-chalcogen bonds in the stochiometric compositions, $\mathrm{S}-\mathrm{S}(\mathrm{Se}-\mathrm{Se})$ in $\mathrm{As}_{2} \mathrm{~S}_{3}\left(\mathrm{As}_{2} \mathrm{Se}_{3}\right)$ binary glasses and only $\mathrm{Se}-\mathrm{Se}$ in As-S-Se ternary glasses, which indicates that Se has a bigger tendency to form chalcogen-chalcogen bonds.

(4) The lack of XPS evidence of As-As bonds is possibly due to the smaller change in the As environment observed by XPS; further research is needed to provide evidence of As-As bonds.

(5) For chalcogen-rich As-S-Se glasses, Raman results show that the molecular structure, similar to the binary glass system $\mathrm{As}_{x} \mathrm{Ch}_{1-x}$, consists of a network of chalcogen chain fragments cross-linked by pyramidal $\mathrm{AsCh}_{3}$ units. The presence of the substantial amount of $\mathrm{S}-\mathrm{S}$, $\mathrm{S}-\mathrm{Se}$, and $\mathrm{Se}-\mathrm{Se}$ bonds is evident through different $\mathrm{Ra}-$ man vibrations.

(6) Supporting the finding in stochiometric composition, in chalcogen-rich system, there are clear evidences to show that when there is extra chalcogen in the system, Se atoms tend to from chalcogen-chalcogen chains, while $S$ prefers to stay in the $\mathrm{AsCh}_{3}$ pyramidal units.

Finally, we conclude that complementary techniques lead to a constant understanding of structure and electronic properties, which allows us to better understand the attractive optical properties of these glasses.

\section{ACKNOWLEDGMENTS}

We would like to thank the National Science Foundation for supporting this work through NSF Grant Nos. DMR9974129 and DMR-0312081. Our appreciation also extends to the Materials Characterization Facility at the University of Central Florida (UCF), the Physics Department at UCF, Zettlemoyer Center for Surface Studies at Lehigh University, and Stanford Synchrotron Radiation Laboratory for their hospitality and staff support.

${ }^{1}$ R. Frerichs, Phys. Rev. 78, 643 (1950).

${ }^{2}$ R. Frerichs, J. Opt. Soc. Am. 43, 1153 (1953).

${ }^{3}$ A. R. Hilton, J. Non-Cryst. Solids 2, 28 (1970).

${ }^{4}$ T. Cardinal, K. A. Richardson, H. Shim, A. Schulte, R. Beatty, K. Le Foulgoc, C. Meneghini, J. F. Viens, and A. Villeneuve, J. Non-Cryst. Solids 256-257, 353 (1999).

${ }^{5}$ D. W. Hall, M. A. Newhouse, N. F. Borrelli, W. H. Dumbaugh, and D. L. Weidman, Appl. Phys. Lett. 54, 1293 (1989).

${ }^{6}$ O. M. Efimov, L. B. Glebov, K. A. Richardson, E. Van Stryland, T. Cardinal, S. H. Park, M. Couzi, and J. L. Bruneel, Opt. Mater. 17, 379 (2001).

${ }^{7}$ A. V. Stronski, M. Vlcek, A. Sklenar, P. E. Shepeljavi, S. A. Kostyukevich, and T. Wagner, J. Non-Cryst. Solids 266-269, 973 (2000).

${ }^{8}$ M. Asobe, K. Suzuki, T. Kanamori, and K. Kubodera, Appl. Phys. Lett. 60, 1153 (1992)

${ }^{9}$ A. Saliminia, A. Villeneuve, T. V. Galstyan, S. LaRochelle, and K. Richardson, J. Lightwave Technol. 17, 837 (1999).

${ }^{10}$ J. M. Harbold, F. O. Ilday, F. W. Wise, J. S. Sanghera, I. D. Aggarwal, and B. G. Aitken, Proc. SPIE 5061, 143 (2003).

${ }^{11}$ W. E. Morgan and J. R. Van Wazer, J. Phys. Chem. 77, 964 (1973).

${ }^{12}$ J. F. Moulder, W. F. Sticker, P. E. Sobol, and K. D. Bomben, Handbook of $X$-Ray Photoelectron Spectroscopy (Perkin-Elmer, Eden Prairie, Minnesota, 1992).

${ }^{13}$ A. V. Kolobov, H. Oyanagi, and K. Tanaka, Phys. Rev. Lett. 87, 145502 (2001).

${ }^{14}$ A. V. Kolobov, H. Oyanagi, K. Tanaka, and K. Tanaka, Phys. Rev. B 55, 726 (1997)

${ }^{15}$ G. Chen, H. Jain, S. Khalid, J. Li, D. A. Drabold, and S. R. Elliott, Solid State Commun. 120, 149 (2001).

${ }^{16}$ J. S. Sanghera, L. B. Shaw, and I. D. Aggarwal, C. R. Chim. 5, 873 (2002).

${ }^{17}$ M. A. Popescu, Non-Crystalline Chalcogenides (Kluwer Academic, Boston, 2000), p. 27.

${ }^{18}$ A. T. Ward, J. Phys. Chem. 72, 4133 (1968).

${ }^{19}$ P. J. S. Ewen, M. J. Sik, and A. E. Owen, Solid State Commun. 33, 1067 (1980).

${ }^{20}$ S. Onari, K. Matsuishi, and T. Arai, J. Non-Cryst. Solids 74, 67 (1985).

${ }^{21}$ M. Malyj, G. P. Espinosa, and J. E. Griffiths, Solid State Commun. 62, 671 (1987)

${ }^{22}$ M. Frumar, Z. Polak, and Z. Cernosek, J. Non-Cryst. Solids 256-257, 105 (1999).

${ }^{23}$ V. Kovanda, M. Vlcek, and H. Jain, J. Non-Cryst. Solids 326-327, 88 (2003).

${ }^{24} \mathrm{~A}$. Schulte and K. Richardson, in Recent Research Developments in NonCrystalline Solids 2, edited by M. Kawasaki, N. Ashgriz, and R. Anthony (Transworld Research Network, Trivandrum, 2002, Vol. 1, 143-158.

${ }^{25}$ C. Rivero, A. Schulte, and K. Richardson, Ceram. Trans. 126, 79 (2002).

${ }^{26}$ R. J. Nemanich, G. A. N. Connell, T. M. Hayes, and R. A. Street, Phys. Rev. B 18, 6900 (1978).

${ }^{27}$ A. Schulte, C. Rivero, K. Richardson, K. Turcotte, V. Hamel, A. Villeneuve, T. Galstian, and R. Vallee, Opt. Commun. 198, 125 (2001).

${ }^{28}$ A. Gheorghiu, I. Lampre, S. Dupont, C. Senemaud, M. A. El Idrissi Raghni, P. E. Lippens, and J. Olivier-Fourcade, J. Alloys Compd. 228, 143 (1995).

${ }^{29}$ E. P. Domashevskaya, V. V. Gorbachev, V. A. Terekhov, V. M. Kashkarov, E. V. Panfilova, and A. V. Shchukarev, J. Electron Spectrosc. Relat. Phenom. 114-116, 901 (2001)

${ }^{30}$ L. Jiang, A. G. Fitzgerald, M. J. Rose, K. Christova, and V. Pamukchieva, J. Non-Cryst. Solids 297, 13 (2002).

${ }^{31}$ M. Bruns, H. Klewe-Nebenius, G. Pfennig, E. Bychkov, and H. J. Ache, Surf. Coat. Technol. 97, 707 (1997). 
${ }^{32}$ J. S. Berkes, S. W. Ing, Jr., and W. J. Hillegas, J. Appl. Phys. 42, 4908 (1971).

${ }^{33}$ A. V. Kolobov, J. Non-Cryst. Solids 164-166, 1159 (1993).

${ }^{34}$ A. V. Kolobov, J. P. S. Badyal, and R. M. Lambert, Surf. Sci. 222, L819 (1989).

${ }^{35}$ T. Kitahara and T. Arai, Jpn. J. Appl. Phys. 18, 1635 (1979).

${ }^{36}$ K. Antoine, J. Li, D. A. Drabold, H. Jain, M. Vlcek, and A. C. Miller, J. Non-Cryst. Solids 326-327, 248 (2003).

${ }^{37}$ H. Jain, S. Krishnaswami, A. C. Miller, P. Krecmer, S. R. Elliott, and M. Vlcek, J. Non-Cryst. Solids 274, 115 (2000).

${ }^{38}$ S. Seal, K. A. Richardson, C. Lopez, A. Graham, D. K. Verma, A. Salimina, T. Galstian, and A. Villeneuve, Phys. Chem. Glasses 43, 59 (2002).

${ }^{39}$ S. Seal, K. A. Richardson, W. Li, C. Lopez, A. Schulte, A. Graham, and C. Rivero, Corrosion (Houston) 59, 139 (2003).

${ }^{40}$ J. M. Durand, J. Olivier-Fourcade, J. C. Jumas, M. Womes, and P. Parent, J. Mater. Sci. 32, 4679 (1997).

${ }^{41}$ J. M. Durand, P. E. Lippens, J. Olivier-Fourcade, J. C. Jumas, and M. Womes, J. Non-Cryst. Solids 194, 109 (1996).

${ }^{42}$ J. M. Durand, P. E. Lippens, J. Olivier-Fourcade, and J. C. Jumas, J. Non-Cryst. Solids 192-193, 364 (1995).

${ }^{43}$ G. Pfeiffer, J. J. Rehr, and D. E. Sayers, Phys. Rev. B 51, 804 (1995).

${ }^{44}$ C. Y. Yang, M. A. Paesler, and D. E. Sayers, Phys. Rev. B 39, 10342 (1989).

${ }^{45}$ Y. Yang, M. A. Paesler, and D. E. Sayers, Phys. Rev. B 36, 9160 (1987).

${ }^{46}$ A. V. Kolobov, K. Tanaka, and H. Oyanagi, Phys. Solid State 39, 64 (1997).

${ }^{47}$ A. M. Flank, D. Bazin, H. Dexpert, P. Lagarde, C. Hervo, and J. Y. Barraud, J. Non-Cryst. Solids 91, 306 (1987).

${ }^{48}$ P. Armand, A. Ibanez, and E. Philippot, Nucl. Instrum. Methods Phys. Res. B 97, 176 (1995)

${ }^{49}$ V. Mastelaro, S. Benazeth, and H. Dexpert, J. Non-Cryst. Solids 185, 274 (1995).

${ }^{50}$ D. G. Georgiev, P. Boolahand, and M. Micoulaut, Phys. Rev. B 62, R9228 (2000).

${ }^{51}$ L. G. Protasova, P. I. Buler, and S. A. Subbotina, Inorg. Mater. (USSR) 25, 659 (1989)

${ }^{52}$ C. Y. Yang, M. A. Paesler, and D. E. Sayers, Phys. Rev. B 36, 980 (1987).

${ }^{53}$ W. Zhou, M. A. Paesler, and D. E. Sayers, Phys. Rev. B 43, 11920 (1989).

${ }^{54}$ J. M. Lee, G. Pfeiffer, M. A. Paesler, D. E. Sayers, and A. Fontaine, J. Non-Cryst. Solids 114, 52 (1989).

${ }^{55}$ J. M. Lee, M. A. Paesler, D. E. Sayers, and A. Fontaine, J. Non-Cryst. Solids 123, 295 (1990).

${ }^{56}$ A. V. Kolobov, H. Oyanagi, K. Tanaka, and K. Tanaka, J. Lumin. 66-67, 174 (1996).

${ }^{57}$ A. V. Kolobov, H. Oyanagi, K. Tanaka, and K. Tanaka, J. Non-Cryst. Solids 198-200, 709 (1996).

${ }^{58}$ J. Li and D. A. Drabold, Phys. Rev. B 64, 104206 (2001).

${ }^{59}$ J. Li, D. A. Drabold, S. Krishnaswami, G. Chen, and H. Jain, Phys. Rev. Lett. 88, 046803 (2002).

${ }^{60}$ G. Lucovsky and R. Martin, J. Non-Cryst. Solids 8-10, 185 (1972).

${ }^{61}$ A. Schulte, Appl. Spectrosc. 46, 891 (1992).
${ }^{62} \mathrm{C}$. Rivero, thesis, University of Central Florida, 2001.

${ }^{63}$ GRAMS User's Guide (Galactic Industries, Salem, NH, 1999).

${ }^{64}$ D. A. Shirley, Phys. Rev. B 5, 4709 (1972).

${ }^{65}$ H. E. Bishop, Surf. Interface Anal. 3, 272 (1981).

${ }^{66}$ J. Vegh, J. Electron Spectrosc. Relat. Phenom. 46, 411 (1988).

${ }^{67}$ B.-K. Teo, in EXAFS Spectroscopy: Techniques and Applications, edited by B. K. Teo and D. C. Joy (Plenum, New York, 1981), p. 17.

${ }^{68}$ D. Schiferl and C. S. Barrett, J. Appl. Crystallogr. 2, 30 (1969).

${ }^{69}$ A. C. Stergious and P. J. Rentzeperis, Z. Kristallogr. 173, 185 (1985).

${ }^{70}$ D. J. E. Mullen and W. Nowaki, Z. Kristallogr. 136, 48 (1972).

${ }^{71}$ A. L. Ankudinov and J. J. Rehr, Phys. Rev. B 56, R1712 (1997).

${ }^{72} \mathrm{http}: / / \mathrm{www}$-ssrl.slac.stanford.edu/exafspak.html

${ }^{73}$ E. Diemann, Rev. Chim. Miner. 16, 237 (1979).

${ }^{74}$ T. Wagner, S. O. Kasap, M. Vlcek, A. Sklenar, and A. Stronski, J. Mater. Sci. 33, 5581 (1998).

${ }^{75}$ D. W. Scott, J. P. McCullough, and F. H. Kruse, J. Mol. Spectrosc. 13, 313 (1964).

${ }^{76}$ P. Nagels, Semiconductors 32, 855 (1998).

${ }^{77}$ A. Feltz and G. Pfaff, J. Non-Cryst. Solids 77-78, 1137 (1985).

${ }^{78}$ G. Lucovsky, Phys. Rev. B 6, 1480 (1972).

${ }^{79}$ P. Boolchand, D. G. Georgiev, T. Qu, F. Wang, L. Cai, and S. Chakravaty, C. R. Chim. 5, 713 (2002).

${ }^{80}$ M. Frumar, J. Jedelsky, B. Frumarova, T. Wagner, and M. Hrdlicka, J. Non-Cryst. Solids 326-327, 399 (2003).

${ }^{81}$ V. I. Mikla, J. Phys.: Condens. Matter 8, 429 (1996).

${ }^{82}$ A. Bertoluzza, C. Fagnano, P. Monti, and G. Semerano, J. Non-Cryst. Solids 29, 49 (1978).

${ }^{83}$ J. Schottmiller, M. Tabak, G. Lucovsky, and A. Ward, J. Non-Cryst. Solids 4, 80 (1970).

${ }^{84}$ T. Mori, S. Onari, and T. Arai, Jpn. J. Appl. Phys. 19, 1027 (1980).

${ }^{85}$ V. I. Mikla, A. A. Baganich, A. P. Sokolov, D. G. Semak, and A. P. Shebanin, Sov. Phys. Solid State 34, 1433 (1992).

${ }^{86}$ V. I. Mikla, A. A. Baganich, A. P. Sokolov, and A. P. Shebanin, Phys. Status Solidi B 175, 281 (1993).

${ }^{87}$ J. A. Freitas, Jr., U. Strom, and D. J. Treacy, J. Non-Cryst. Solids 59-60, 875 (1983).

${ }^{88}$ S. Onari, H. Saegusa, T. Mori, and T. Arai, J. Non-Cryst. Solids 59-60, 871 (1983).

${ }^{89}$ R. Zallen, M. L. Slade, and A. T. Ward, Phys. Rev. B 3, 4257 (1971).

${ }^{90}$ G. Lucovsky, in The Physics of Selenium and Tellurium, edited by E. Gerlach and P. Grosse (Springer, Berlin, 1979), p. 210.

${ }^{91}$ M. L. Slade and R. Zallen, Solid State Commun. 30, 357 (1979).

${ }^{92}$ D. J. Treacy, U. Strom, P. B. Klein, P. C. Taylor, and T. P. Martin, J. Non-Cryst. Solids 35-36, 1035 (1980).

${ }^{93}$ J. A. Freitas, Jr., U. Strom, and D. J. Treacy, J. Non-Cryst. Solids 59-60, 875 (1983)

${ }^{94}$ K. Hattori and H. Kawamura, J. Non-Cryst. Solids 59-60, 1063 (1983).

${ }^{95}$ A. Kolobov, H. Oyanagi, A. Roy, and K. Tanaka, J. Non-Cryst. Solids 227-230, 710 (1998).

${ }^{96}$ A. T. Ward, J. Phys. Chem. 74, 4110 (1970).

${ }^{97}$ N. J. Shevchik, M. Cardona, and J. Tejeda, Phys. Rev. B 8, 2833 (1973). 